\title{
Accounting for business combinations: Do purchase price allocations matter?
}

Luc Paugam $^{1}$

paugam@essec.edu $0033(0) 134433758$

ESSEC Business School

Department of Accounting and Management Control

Avenue Bernard Hirsch, 95021 Cergy-Pontoine, France

\section{Pierre Astolfi}

pierre.astolfi@u-pec.fr

University Paris-Est Créteil

IAE Gustave Eiffel

61 avenue du Général de Gaulle, 94010 Créteil Cedex, France

Olivier Ramond

olivier.ramond@dauphine.fr

University Paris-Dauphine

DRM Finance

Place du maréchal de Lattre de Tassigny, 75016 Paris, France

Forthcoming in Journal of Accounting and Public Policy

${ }^{1}$ Corresponding author 


\title{
Accounting for business combinations: Do purchase price allocations matter?
}

\begin{abstract}
This study investigates the informativeness of purchase price allocations (PPAs) that involve fair value estimation of acquired assets and liabilities after a business combination. Using a model capturing the amount of goodwill expected after the initial announcement of an acquisition, we examine how allocation of abnormal levels of purchase price to goodwill (Abnormal Goodwill) affects stock price reaction surrounding the first disclosure of the PPA in SEC filings, and the acquirer's future performance. From a sample of 308 economically significant U.S. business combinations completed between 2002 and 2011, we document the following results: (1) Abnormal Goodwill is negatively associated with cumulative abnormal returns surrounding the first disclosure of the PPA, (2) there is a stronger negative reaction to Abnormal Goodwill for acquisitions that were already negatively received by market participants when initially announced than for acquisitions that were initially received positively, (3) the frequency and magnitude of goodwill impairment during the three years following completion of the acquisition increases as Abnormal Goodwill increases, and (4) future performance decreases as Abnormal Goodwill increases. Overall, our findings indicate that Abnormal Goodwill is informative regarding the quality of acquisitions. This study contributes to the debate on the usefulness of PPA.
\end{abstract}

Keywords: Purchase Price Allocation, Abnormal Goodwill, Market Expectations, Business Combinations, SFAS 141.

JEL classification: G32, G34, M41. 


\section{Introduction}

Financial reporting allows capital providers to assess the return potential of investment opportunities and to monitor managers' important decisions such as mergers and acquisitions. Recent proposals by the U.S. and international standard-setters resulted in a major change in business combination accounting treatment: the purchase price of the target entity must now be allocated to the fair values of identifiable tangible and intangible assets, such as trademarks, technology, customer relationships and order backlogs, in order to provide relevant information about acquisitions (SFAS 141 and IFRS 3). ${ }^{2}$ The process for identifying and valuing acquired tangible and intangible assets, namely purchase price allocation (hereafter PPA), requires goodwill to be considered as the residual of the consideration paid. According to the FASB, PPA should "provide users with a better understanding of the resources acquired and improve their ability to assess future profitability and cash flows"3. However, questions have been raised about the usefulness of the information provided under the joint FASB and IASB position relating to PPAs. The standard-setters are not completely supported by certain academics and users of financial information, who are concerned about the relevance of recognizing intangible assets separately from goodwill, and the quality of fair value measurement of intangible assets. ${ }^{4}$ Reliance on subjective fair value estimates makes PPA prone to manipulation, which potentially reduces its informativeness for investors.

In this paper, we address the following question: is PPA useful for investors? To address this question, we examine: (1) whether market participants take into consideration (react to) the information content of PPAs disclosed by acquirers, particularly the level of goodwill resulting from the PPA, to revise their expectations about the risk, amount and timing of future cash flows; (2) whether the information content of PPAs, if any, is informative about the quality of acquisitions.

In order to isolate the effects of PPA on investors' capital allocation decisions, we examine market participants' reaction to an abnormal level of purchase price allocated to goodwill (Abnormal Goodwill). All else equal, the subjectivity involved in estimating intangibles' fair values coupled with management's incentives to manipulate PPA can lead to

\footnotetext{
${ }^{2}$ SFAS 141 is now included in the Accounting Standards Codification (ASC) paragraphs 805-10-50 and 805-3050.

${ }^{3}$ http://www.fasb.org/summary/stsum141.shtml

${ }^{4}$ See Garten (2001), Kanodia et al. (2004), Skinner (2008), and Penman (2009) on the usefulness for investors of requiring separate recognition of (non-goodwill) intangible assets. See also Ball (2006), Shalev (2009) and Shalev et al (2013), who argue that PPAs are open to manipulation. We review their arguments in more detail in the literature review.
} 
variations in the amount of purchase price that is allocated to goodwill, which is a "plug-in" number in PPA (Shalev et al., 2013). Abnormal Goodwill could also capture the quality of acquisitions, since goodwill mechanically subsumes any overpayment. The abnormal amount of recognized goodwill captures deviations from the expected purchased goodwill. We define Expected Goodwill as the level of purchase price allocated to goodwill that is consistent with the economic fundamentals of the acquisition and investors' expectations of synergies and overpayment at the time of announcement of the acquisition. Expected Goodwill is affected by four factors: (1) revaluation (fair value adjustments) of the target's tangible assets and identification and valuation of intangible assets not previously recognized by the target, (2) the target's going concern (internally generated) goodwill, reflecting its performance and growth opportunities as a stand-alone entity, (3) the expected synergies between the acquirer and the target resulting from the combination, and (4) the expected overpayment for the target firm (Henning et al., 2000; Johnson and Petrone, 1998; Zanoni, 2009).

We measure Abnormal Goodwill as the difference between observed goodwill and Expected Goodwill predicted from a model capturing factors (1) to (4) above upon announcement of the acquisition and sector characteristics (Kimbrough, 2007; Shalev, 2009; Shalev et al., 2013). Abnormal Goodwill is the amount of purchase price allocated to goodwill that differs from the Expected Goodwill, considering the underlying economics of the acquisition, i.e., fair value adjustments, the target's going concern goodwill, expected synergies between the acquirer and the target, and expectation of overpayment upon announcement of the acquisition. We test the association between Expected Goodwill, Abnormal Goodwill and cumulative abnormal returns surrounding the first disclosure of the PPA in acquirers' $10-\mathrm{Q}$ or $10-\mathrm{K}$ filings released after completion of the acquisition (Kimbrough, 2007). The PPA can be released up to two years after the announcement of the acquisition. Higher levels of Abnormal Goodwill could signal two (negative) underlying factors: (1) overallocation of purchase price to goodwill, to artificially increase future earnings - as goodwill, unlike intangible assets, is not amortized but tested for impairment, (2) unexpected overpayment for the target firm, i.e., above market participants' initial expectations of overpayment at the time of the announcement, resulting in higher than anticipated goodwill. Figure 1 describes the timeline of a typical acquisition and our general empirical strategy.

[Insert Figure 1 About Here] 
To distinguish between these two factors, we examine whether investors' reaction to Abnormal Goodwill is different for deals that were already negatively received by market participants when initially announced (Bad Deals) and deals that were positively received by market participants when initially announced (Good Deals). We use acquirer's stock returns around the announcement of the acquisition to differentiate Bad Deals from Good Deals. We hypothesize that if there is a stronger negative investor reaction to Abnormal Goodwill for Bad Deals, this indicates that investors revise their beliefs regarding the extent of overpayment upwards when the PPA is disclosed and Abnormal Goodwill becomes known to market participants. The reaction to any perceived overallocation of purchase price to goodwill is likely to be independent of the type of deal. Next, we examine whether Abnormal Goodwill is informative about the quality of acquisitions. We test to see whether Abnormal Goodwill is associated with the frequency and magnitude of future goodwill impairment after completion of the acquisition, and whether it is associated with changes in the acquirer's future operating performance.

Our empirical analysis is conducted on a hand-collected dataset of PPAs from acquirers' quarterly and annual reports, concerning 308 economically significant U.S. acquisitions with a purchase price in excess of $\$ 100$ million, completed between 2002 and 2011 . We document the following results. First, we provide evidence that Abnormal Goodwill is significantly negatively related with cumulative abnormal returns surrounding the first disclosure of the PPA in SEC filings, while Expected Goodwill is unrelated to cumulative abnormal returns. This result suggests that market participants react negatively to higher levels of Abnormal Goodwill, and vice versa. It also demonstrates that investors respond to the information content of PPAs disclosed by acquirers by revising their expectations about the consequences in terms of the amount, timing and risk of future cash flows following acquisitions. Second, we show that investors' negative reaction to Abnormal Goodwill is stronger for Bad Deals than for Good Deals. This suggests that investors examine the level of Abnormal Goodwill to revise their initial estimate of overpayment for the target firm, but do not seem to react to management overallocating purchase price to goodwill. Third, we demonstrate that the frequency and magnitude of future goodwill impairment during the two to three years following completion of the acquisition increases as Abnormal Goodwill increases. Finally, we show that Abnormal Goodwill is negatively associated with future changes in the acquirer's operating performance. These results suggest that Abnormal Goodwill resulting 
from PPA is informative about the quality of acquisitions, and that Abnormal Goodwill is positively correlated with unexpected overpayment.

Our study makes several contributions to the literature. First, we add to the literature showing the relevance of disclosures about business combinations, and PPAs in particular (Kimbrough, 2007; Shalev, 2009). This is a key contribution to the current debate between academics and standard-setters regarding the informativeness for investors of accounting for business combinations. Second, our study provides evidence on the type of information conveyed by PPA. We are able to identify why investors react to the information content of PPA, as we show that the negative reaction to Abnormal Goodwill is due to revision of investors' initial beliefs regarding overpayment. Third, we add to the literature examining the quality of acquisitions and determinants of goodwill impairment (e.g., Gu and Lev, 2011; Hayn and Hughes, 2006), since we demonstrate that Abnormal Goodwill is positively associated with the frequency and magnitude of future goodwill impairment, and negatively associated with changes in the acquirer's future performance.

The remainder of this paper proceeds as follows. We summarize the related literature and present our research questions in section 2. We develop our hypotheses in section 3 . We describe the empirical strategy in section 4 . We present our data and report our findings in section 5. Robustness checks are discussed in section 6, and section 7 concludes the study.

\section{Literature review and research questions}

We first review the rules on the accounting treatment for business combinations, which have considerably evolved over the past ten years as the purchase price allocation practice has become mandatory in the U.S. and internationally. Next, we discuss the arguments of academics and some users of financial information regarding PPA, arguing that: (1) at best, it provides investors with useless information about intangible assets, and (2) it can actually impair the usefulness of financial statements since it may be used for earnings management. Finally, we formulate our research questions regarding the usefulness of PPA for investors.

\subsection{Business combination accounting treatment: Towards separate recognition for goodwill} and other intangible assets

The accounting treatment of business combinations under U.S. GAAP has been very controversial ever since the Accounting Principles Board issued APB 16 (AICPA, 1970a) and APB 17 (AICPA, 1970b), respectively dedicated to business combinations and intangible 
assets. In 2001, the Financial Accounting Standards Board (FASB) clearly indicated its preference for recognizing goodwill separately from other intangible assets by publishing Statement of Financial Accounting Standards No. 141 (SFAS 141), 'Business Combinations' (FASB, 2001). Three years later, the International Accounting Standards Board (IASB) converged towards this position in International Financial Reporting Standard No. 3 (IFRS 3), also entitled 'Business Combinations' (IASB, 2004). At the time, the IASB insisted that distinguishing intangible assets acquired in a business combination from the goodwill on the operation would enhance the usefulness of financial statements (IASB 2004 §C89).

The FASB reaffirmed this view more recently as part of the joint convergence project between U.S. and international GAAP, stating: "Both the IASB and the FASB decided that they needed to provide explicit criteria for determining whether an acquired intangible asset should be recognized separately from goodwill. The FASB provided such criteria in SFAS 141 and the IASB provided similar, although not identical, criteria [...]. One reason for providing such criteria was the boards' conclusion that the decision-usefulness of financial statements would be enhanced if intangible assets acquired in a business combination were distinguished from goodwill” (FASB $2007 \S$ BC158).

Some academics support the joint IASB/FASB position in favor of separate recognition of intangible assets and fair value measurement of goodwill. Kimbrough (2007) examines the effects of adoption of SFAS 141 on the informativeness of approximately 440 PPAs. He tests the association between the relative price paid to acquire the target, defined as the consideration paid divided by the acquirer's market value, and cumulative abnormal returns surrounding the first disclosure of the PPA in SEC filings. He finds that the positive association between the relative price paid and the absolute value of cumulative abnormal returns increased after the adoption of SFAS 141. Kimbrough (2007) also presents evidence that investors react negatively (positively) to PPAs resulting in high levels of recognized goodwill (separately identified intangibles). He argues that this is because goodwill is a composite asset that commingles several elements (e.g., the target's going concern goodwill, unrecognized intangible assets, external synergies) that are hard to disentangle, and is relatively less informative to market participants than separately identified intangible assets.

Building on this methodology, this paper examines the association between Expected Goodwill, Abnormal Goodwill and cumulative abnormal returns, and finds results consistent with Kimbrough. However, we argue that Abnormal Goodwill brings out two other possible factors: earnings management-driven overallocation of purchase price to goodwill (Shalev et 
al., 2013), and unexpected overpayment. Our results support this third explanation of investors' negative reaction to purchased goodwill.

Lee (2011) also supports the standard-setter's position on subsequent valuation of purchased goodwill. Focusing on the new impairment regime introduced by SFAS $142,{ }^{5}$ he shows that goodwill's ability to predict future cash flows has increased since the discontinuation of systematic amortization, and that goodwill fails to reveal opportunistic use of discretion under SFAS 142.

However, other academics and professional users of financial information have concerns regarding the usefulness and quality of financial statements disclosed under SFAS 141 and its revised version, SFAS 141R, released in December 2007, indicating that the FASB's objective of usefulness is not fully achieved.

\subsection{Concerns over the usefulness of PPAs: Separate recognition of intangible assets}

Various academics including Jennings et al. (1996), Kanodia et al. (2004), Skinner (2008), and Penman (2009), and some investors, ${ }^{6}$ support the view that the information disclosed on intangible assets reported separately from goodwill in application of SFAS 141 has only limited relevance for market participants.

In a report on strengthening financial markets published as early as 2001, Garten (2001) casts doubt on the real impact of accounting for intangible assets on equity valuation. He explains that firm value is driven by its perceived ability to generate profits and cash flow and that intangible assets, by helping companies generate profits and cash flow, are a key indirect driver of value. However, he argues that this does not necessary imply that the value of a company's intangible assets translates directly into the value of the company as a whole. From a valuation perspective, Penman (2009) points out that as intangibles generate wealth for companies, economic benefits eventually flow through the income statement, allowing financial statement users to assess the contribution made by intangible assets to firm value.

Skinner (2008) challenges the usefulness of accounting and disclosures pertaining to intangible assets for equity valuation while arguing that intangible projects, especially those conducted in the high-technology and innovative sectors, raise no specific financing issues

\footnotetext{
${ }^{5}$ SFAS 142 is now codified in ASC 350.

${ }^{6}$ See the IASB/FASB Joint Board Meeting of the CRUF, April 22, 2008. The CRUF (Corporate Reporting Users' Forum) was formed in 2005 and represents the interests of professional investors and analysts from around the world in the financial reporting debate.
} 
and therefore do not need further disclosures. Similarly, Maines et al. (2003), referring to Holthausen and Watts (2001), advocate that the rarity of voluntary disclosures of intangibles information by listed companies is evidence of the relatively small net private benefits those firms stand to gain from disclosing. Kanodia et al. (2004) also underline that intangible assets, even when not separately identified, may be properly valued by market participants. They propose a model that incorporates the FASB's concerns regarding the reliability of the value of intangible assets, assuming that measurement of intangibles is "necessarily noisy", and point out that "Empirical studies document a positive association between estimated intangible investments and stock prices and returns even when the accounting system does not explicitly measure and report intangibles." They add that their results do not necessarily imply that incorporating such estimates into financial statements would actually provide new information to the market, nor do they imply that an outside observer could use these estimates to identify mispriced stocks and earn excess returns in the market.

Like Kanodia et al. (2004), Skinner (2008) argues that the main explanation for the difference between book value and market value is not the value of unrecognized intangible assets, since investors can properly value intangible assets even when they are not recognized in the balance sheet. The argument of Kanodia et al. (2004) and Skinner (2008) thus contrasts with the idea that even a crude estimate for intangibles would be better than nothing. They argue that in some circumstances, an inaccurate estimate for intangible assets may result in "noise" that the market will seek to undo. This noise may be not only useless, but could prevent correct valuation by investors. In particular, Kanodia et al. (2004) advocate that measurement of intangible assets should be enforced only when those assets represent a significant part of the firm's capital stock and their value is measurable with a sufficient degree of accuracy. This is consistent with the international accounting standard-setter's initial position in IFRS 3 (IASB, 2004), which until its revision in 2008 stipulated that intangible assets could only be recognized if their fair value could be measured reliably. This position has since been reversed by the IASB in IFRS 3R (IASB, 2008), which assumes that all intangible assets emerging from a business combination can be measured reliably. Basu and Waymire (2008) also argue that intangibles are cumulative, synergistic, and frequently inseparable from other tangible assets and/or economic intangibles not owned by any single entity, and cast doubt on the possibility of meaningful estimates of the individual values of economic and cultural intangibles that contribute to firm value. 


\subsection{Concerns over PPA and earnings management}

In addition to the concerns regarding the relevance of recognizing specific intangibles, there are concerns that PPAs are likely to favor earnings management behaviors. Before SFAS 141 was issued in 2001 (FASB, 2001), earnings management in business combinations consisted in optimizing the choice of accounting method: purchase method vs. pooling of interests method. Many firms preferred the pooling of interests method, arguably because of its more favorable effect on future earnings compared to the purchase method (Dunne, 1990). ${ }^{7}$ Some studies (Browning, 1997; Hopkins et al., 2000; McGoldrick, 1997) demonstrate that stock prices for firms that used the purchase accounting method were penalized compared with those of companies that were able to use the pooling treatment - although other studies (e.g., Jenkins, 1999; Jennings et al., 1996; Vincent, 1997) document that investors are unlikely to be misled by such a non-cash accounting treatment. Under the efficient market hypothesis, the price paid is assumed to be the same, however favorable the accounting treatment in terms of financial presentation.

Since SFAS 141, earnings management in business combinations has consisted in optimizing the value of intangible assets in order to minimize the impact of their amortization on subsequent earnings. Unlike most intangible assets that have a finite useful life, goodwill is not amortized but tested for impairment, and therefore does not systematically reduce future earnings. The U.S. and international standard-setters acknowledged in 2008, the year the revised IFRS 3 was issued (IASB, 2008), that the previous standard (IFRS 3) had not been properly applied (IASB $2008 \S$ BC 157): "Early in their respective projects on accounting for business combinations, the IASB and the FASB both observed that intangible assets make up an increasing proportion of the assets of many (if not most) entities. The boards also observed that intangible assets acquired in a business combination were often included in the amount recognized as goodwill." The Boards thus acknowledged that, at least until the revision of SFAS 141 and IFRS 3, the standards did not achieve the objective of reducing the proportion of goodwill recognized in connection with a business combination, and this negatively affected the quality of financial statements.

Shalev (2009), analyzing a U.S. sample of 713 business combinations, demonstrates that the quality of information disclosed on PPA actually varies widely. He also shows that disclosure is predictably associated with the proportion of Abnormal Goodwill resulting from

\footnotetext{
${ }^{7}$ Under the pooling of interests approach, the acquirer did not recognize goodwill. Therefore, there was no amortization expense for goodwill pre-SFAS 142.
} 
the PPA. Zhang and Zhang (2014) highlight that the end of the pooling of interests method after the issue of SFAS 141 in 2001 did not put an end to the controversy or attention surrounding this issue. The debate merely shifted, to focus on the extent to which the new standards might exacerbate earnings management to minimize the impact of amortization expenses on future net income. The incentive to manage earnings arose because the end of the pooling of interests method was concurrent with the end of goodwill amortization. This results in the possibility of opportunistic behaviors seeking to optimize the initial PPA by recognizing more non-amortizable assets (goodwill) than amortizable assets (other intangible assets), in order to decrease the systematic future impact on earnings. Shalev et al. (2013) show, from a sample of approximately 300 acquisitions, that CEOs whose compensation is relatively more affected by earnings tend to recognize more goodwill, after controlling for economic factors affecting the level of purchase price allocated to goodwill.

Such earnings management behavior is potentially further encouraged by the idea that SFAS 142 on goodwill impairment leads to financial statements based on unverifiable fair value estimates and highly subjective appreciations (Hayn and Hughes, 2006; Li and Sloan, 2014; Ramanna, 2008; Ramanna and Watts, 2012; Watts, 2003). The incentive to use discretion to delay or avoid goodwill impairment is high, as goodwill write-down announcements have a negative impact on stock prices (Hirschey and Richardson, 2002) and management reputation (Francis et al., 1996). Impairment of goodwill reflects management's inability to extract value from past acquisitions. According to Ramanna and Watts (2012), "Agency theory predicts managers (all else equal) will on average use unverifiability in accounting judgment, such as that in SFAS 142 impairment tests, to opportunistically manage financial reports."

Ball (2006) similarly argues that the quality of financial statements is largely impacted by the margin for manoeuvre available to managers to manipulate their financial statements. The new IFRS 3 and SFAS 141R offer issuers even greater latitude for opportunistic management of operating profits: the characteristics of the assets most concerned by IFRS 3 and SFAS $141 \mathrm{R}$, i.e., intangible assets, often require fair value to be assessed by a model when there is no liquid reference market.

The complexity of intangible assets explains some of the concerns expressed in the literature about the usefulness of the information financial reports supply on such assets. Zhang and Zhang (2014), from a sample of 103 deals, predict and find that managers allocate more purchase price to goodwill relative to amortizable intangibles post-SFAS 141, to reduce 
amortization expenses, when they anticipate greater discretion in future goodwill assessment to avoid reporting impairment. They assert that management's reporting opportunism is a much more relevant driver of purchase price allocation than the underlying economics of the acquisition.

In issuing standards requiring residual goodwill to be recognized separately from other intangible assets, the standard-setters simply seem to have encouraged replacement of one type of opportunistic earnings management behavior (application of the pooling of interests method) by another (reduction of the amortization expense by recognizing more goodwill and fewer intangible assets with a finite useful life). Some professional financial statement users have also made this argument. For example, according to the Corporate Reporting Users' Forum (2008): "The creation of new intangibles on acquisition (customer lists, brands, developed technology, etc.) is a return to goodwill amortization by the backdoor but [...] it is even more arbitrary (choice of what to capitalize and amortization period is highly subjective)."

\subsection{Research questions}

This study addresses the current debate between: (1) standard-setters' claims that PPAs provide relevant information for equity valuation, and (2) academics' and financial information users' concerns regarding the actual usefulness of PPA. We examine the following research question:

RQ1: Are PPAs informative for investors in terms of the amount, timing and risk of future cash flows associated with acquisitions?

To answer this research question, we analyze whether and how investors react to an abnormal level of purchase price allocated to goodwill. A reaction to Abnormal Goodwill would directly indicate that the information content of PPA is processed by and relevant to investors. We also attempt to identify whether Abnormal Goodwill resulting from PPA conveys information about the quality of the acquisition, as intended by the standard-setters.

RQ2: What is the information content conveyed by Abnormal Goodwill?

\section{Development of Hypotheses}

The accounting standard-setters claim that allocating the purchase price to acquired assets is useful to investors. The FASB argues that the information content of PPA can influence capital allocation decisions taken by investors. Standard-setters generally argue that the fair 
value of the resources underlying the consideration paid, which are identified in the PPA, have implications for the amount, timing and risk of future cash flows.

However, PPA information content may be systematically overlooked by investors for three reasons: (1) investors may view PPA merely as an ex post compliance accounting exercise that comes too late, being finalized up to a year after completion of the acquisition and up to two years after its announcement (see Figure 1$),{ }^{8}(2)$ the valuation methods used to separate intangibles from goodwill may be unreliable because they are based on multiple fair value estimates and could therefore give inaccurate values, and (3) the estimates prepared by managers are potentially not only inaccurate, but also deliberately biased because they could be driven by earnings management incentives.

The most direct evidence of a change in investors' expectations is a price reaction surrounding the first disclosure of new information. To test whether PPAs are informative for market participants, we estimate the level of Expected Goodwill by investors upon initial announcement of the acquisition, and examine the association between the abnormal amount of purchase price allocated to goodwill (Abnormal Goodwill) and cumulative abnormal returns surrounding the first disclosure of the PPA in SEC filings. Higher levels of Abnormal Goodwill indicate either that future earnings are being managed upwards (overallocation of purchase price to goodwill) or that an excessive amount was paid for the target firm and resulted in greater than expected goodwill. These two underlying factors are negative news, and should have a negative effect on stock returns if PPAs are considered informative by market participants. Therefore, hypothesis 1 is as follows:

H1: There is a negative association between Abnormal Goodwill and market returns surrounding the first disclosure of PPA in SEC filings.

To distinguish between a reaction to overallocation of purchase price to goodwill (earnings management) and a reaction to an unexpected overpayment, we examine whether investors' response to Abnormal Goodwill differs across two types of acquisitions, i.e., acquisitions that were positively received by investors when initially announced (Good Deals) vs. acquisitions that were negatively received by investors when initially announced (Bad Deals). Acquirers' stock returns around acquisition announcements generally indicate how the market perceives

\footnotetext{
${ }^{8}$ This position can be illustrated by Aswath Damodaran's comments on his blog regarding the HP-Autonomy deal of 2012: "After acquisitions, accountants are given a limited mission of reappraising the value of existing assets and this appraisal led to an adjusted book value." See: http://www.wallstreetoasis.com/blog/hps-dealfrom-hell-the-mark-it-up-and-write-it-down-two-step.
} 
the deal: a positive stock reaction suggests that the operation is considered a Good Deal creating value for shareholders, and a negative reaction suggests it is considered a Bad Deal destroying shareholder value. If Abnormal Goodwill captures unexpected overpayment, the reaction upon disclosure of the PPA should be more pronounced for Bad Deals. In this case the negative reaction probably reflects a revision of the extent of overpayment initially estimated at the time of the first announcement of the deal (sometimes up to two years before disclosure of the PPA, see Figure 1). Conversely, if investors are reacting to an earnings management-driven overallocation of purchase price to goodwill, the reaction is unlikely to be conditional on the type of acquisition. We therefore test the following hypothesis:

H2: Investors' (absolute) negative reaction to Abnormal Goodwill is greater for transactions negatively received by market participants when initially announced (Bad Deals) than for transactions positively received by market participants when initially announced (Good Deals).

We also examine whether Abnormal Goodwill conveys information about the quality of acquisitions. If Abnormal Goodwill is informative about the extent of unexpected overpayment, it should be positively associated with the frequency and magnitude of subsequent goodwill impairment and negatively associated with subsequent changes in operating performance. We therefore test the following two hypotheses:

H3: The frequency and magnitude of future goodwill impairment following completion of the acquisition increase as Abnormal Goodwill resulting from PPA increases.

H4: The average performance of the acquirer following completion of the acquisition decreases as Abnormal Goodwill resulting from PPA increases.

\section{Empirical strategy}

This section explains how we measure Expected Goodwill and Abnormal Goodwill, and how we test their association with change in investors' expectations, the frequency and magnitude of future impairment and future change in the acquirer's performance.

\subsection{Determinants of Expected Goodwill}

We focus on one aspect of accounting for business combinations, namely the management decision that separates goodwill from the target's tangible assets and other 
identifiable intangible assets. Goodwill is a major observable and measurable variable that is highly dependent on the potential informativeness of PPA. ${ }^{9}$

The amount of purchased goodwill is affected by four factors identified in the literature (Henning et al., 2000; Johnson and Petrone, 1998; Zanoni, 2009). First, purchased goodwill is affected by any fair value adjustments to tangible assets, and identification and recognition of new intangible assets such as technologies, brands, trademarks, order backlogs, etc. Second, purchased goodwill is impacted by the ability of the acquired company, as a stand-alone entity, to earn a higher rate of return on an organized collection of net assets than if those assets had to be acquired separately (reflecting the target's "going concern" or "internally generated" goodwill). Third, purchased goodwill is driven by the value of the synergies expected to arise between the target and the acquiring companies (also known as "combination" goodwill). Lastly, any overvaluation of the target firm resulting in an excessive purchase price has a positive impact on purchased goodwill. Henning et al. (2000) suggest a technology to compute estimates of these three components of purchased goodwill ("going concern" goodwill, synergies and overpayment) once the actual goodwill figure becomes available. They examine whether the various components of goodwill are value relevant, i.e., predictably associated with market value. From a sample of acquisitions accounted for under the purchase method from 1990-1994 they show that the various components of purchased goodwill are associated with market value.

In our study, we use a different technology. We do not attempt to break down goodwill into its different components, but to ascertain whether and why investors react to the information content of PPAs. Our empirical work is therefore based on a market expectation model and an event study. First, we estimate the amount of purchased goodwill that is expected to emerge from the business combination upon the initial announcement of an acquisition. Next, we investigate investors' reaction to Expected Goodwill and Abnormal Goodwill (unexpected goodwill) around the release of the PPA. To our knowledge, Shalev (2009) was the first to introduce the concept of Abnormal Goodwill. This concept is based on the idea that purchase price allocation should lead to recognition of a level of goodwill consistent with the underlying economics of the acquisition and the expectations of market

\footnotetext{
${ }^{9}$ There are other important aspects of accounting for business combinations. For instance, under SFAS 141, acquirers must decide how to allocate the acquired assets, including goodwill, to various operating units. The allocation of purchased goodwill to different operating units is also likely to be informative, but it is impossible in practice to measure any distortion from the expected allocation because the appropriate allocation is impossible to establish ex ante.
} 
participants (e.g., identifiable intangible assets of the target, performance of the target, expected growth, sector characteristics, expected synergies, expected overpayment).

Shalev et al. (2013) identify various underlying factors affecting the expected amount of purchased goodwill at the time of the initial announcement. Model (1) facilitates estimation of the level of Expected Goodwill:

$$
\begin{aligned}
& \text { GOODWILL }_{\mathrm{i}}=\alpha_{0}+\alpha_{1} \mathrm{TRG}_{-} \mathrm{RD}_{\mathrm{i}}+\alpha_{2} \mathrm{TRG}_{-} \mathrm{AD}_{\mathrm{i}}+\alpha_{3} \mathrm{TRG}_{-} \mathrm{BS} \_ \text {GDWL } \mathrm{i} \\
& +\alpha_{4} \text { TRG_BS_INTAN }{ }_{i}+\alpha_{5} \text { TRG_PPE }_{\mathrm{i}}+\alpha_{6} \mathrm{TRG}_{-} \mathrm{MTB}_{\mathrm{i}} \\
& +\alpha_{7} \mathrm{TRG}_{-} \mathrm{SAL} \_\mathrm{GRO}_{\mathrm{i}}+\alpha_{8} \mathrm{TRG}_{-} \mathrm{ROA}_{\mathrm{i}}+\alpha_{9} \mathrm{ACQ}_{-} \mathrm{MTB}_{\mathrm{i}} \\
& +\alpha_{10} \text { TRG_RET_DV } i+\alpha_{11} \text { ACQ_RET_DV } i+\alpha_{12} I_{\text {IND_SAME }} \\
& +\alpha_{13} \text { DEAL_SIZE }_{\mathrm{i}}+\text { Year dummies }+ \text { Target industry dummies }+\varepsilon
\end{aligned}
$$

where for transaction $i$ :

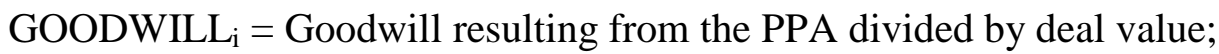

TRG_RD $\mathrm{i}_{\mathrm{i}}=$ Target's $\mathrm{R} \& \mathrm{D}$ expense over the year before the deal announcement divided by deal value;

TRG_AD $\mathrm{D}_{\mathrm{i}}=$ Target's advertising expense over the year before the deal announcement divided by deal value;

TRG_BS_GDWL $L_{i}=$ Target's pre-acquisition goodwill at the year-end prior to the deal announcement divided by deal value;

TRG_BS_INTAN ${ }_{\mathrm{i}}=$ Target's pre-acquisition other intangible assets at the year-end prior to the deal announcement divided by deal value;

TRG_PPE $E_{\mathrm{i}}=$ Target's gross property plant $\&$ equipment at the year-end prior to the deal announcement divided by deal value;

TRG_MTB $_{\mathrm{i}}=$ Target's market-to-book ratio at the year-end prior to the deal announcement;

TRG_SAL_GRO ${ }_{i}=$ Target's average sales growth over the two years before the deal announcement year;

TRG_ROA $A_{i}=$ Target's EBITDA over the year before the deal announcement divided by total assets at the beginning of the year;

ACQ_MTB ${ }_{i}=$ Acquirer's market-to-book ratio at the year-end prior to the deal announcement;

TRG_RET_DV $i=$ Target's dollar amount of stock return over the three-day window around the deal announcement divided by deal value; 
ACQ_RET_DV $V_{i}=$ Acquirer's dollar amount of stock return over the three-day window around the deal announcement divided by deal value ${ }^{10}$

INDSAME $_{\mathrm{i}}=1$ if the acquirer and the target are from the same GICS sector, and 0 otherwise;

DEAL_SIZE $E_{i}=$ natural logarithm of deal value;

$\varepsilon_{\mathrm{i}}=$ error term in model (1) for each transaction $i$.

We capture the target's unrecognized identifiable intangible assets and other fair value adjustments with the following variables: target's R\&D expense (TRG_RD), target's advertising expense (TRG_AD), target's tangibility of the balance sheet (TRG_PPE), target's sales growth (TRG_SAL_GRO) and intangibles recognized on the target's balance sheet before the transaction (TRG_BS_GDWL and TRG_BS_INTAN).

We expect the following association with GOODWILL based on (Shalev et al., 2013). Developed technologies are likely to be positively correlated with R\&D expenditures, therefore we expect the target's pre-acquisition R\&D intensity (TRG_RD) to be negatively associated with GOODWILL. Customer base is positively correlated with sales growth, therefore we predict that TRG_SAL_GRO is negatively associated with GOODWILL. Brand value is usually positively correlated with advertising expenditures, therefore we expect a negative association between TRG_AD and GOODWILL. In allocating the purchase price to acquired assets, acquirers are also required to adjust assets already recognized by the target to fair value. Since property, plant and equipment are generally booked at historical cost, we expect they are more likely to be subject to a fair value step-up, decreasing the amount allocated to goodwill. We thus expect a negative association between TRG_PPE and GOODWILL. Goodwill resulting from past acquisitions by the target firm is likely to remain part of unidentifiable intangible assets. Consequently, following (Shalev et al., 2013), we predict a positive association between TRG_BS_GDWL and GOODWILL. The target's existing intangible assets other than goodwill (TRG_BS_INTA) can be negatively or positively associated with GOODWILL: intangible assets tend to generate synergies with other assets (Basu and Waymire, 2008) and thus have a positive effect on GOODWILL, but they could also lead to recognition of other intangible assets separated from goodwill, and thus have a negative effect on GOODWILL. We include target industry dummies since

\footnotetext{
${ }^{10}$ We follow the same approach as in Shalev et al. (2013) to compute ACQ_RET_DV ${ }_{\mathrm{i}}$ and TRG_RET_DV $\mathrm{i}_{\mathrm{i}}$ in order to adjust for different sizes (market values) between the acquirer and the target firm.
} 
different industries can have different levels of unrecognized intangible assets that may not be captured by other economic variables identified above.

We capture the amount of the target's "going concern" goodwill using the target's market-to-book ratio (TRG_MTB) and its return on assets (TRG_ROA). TRG_MTB is positively correlated with the target's going-concern value and is expected to be positively associated with GOODWILL. TRG_ROA captures the target's performance; it is also positively correlated with the amount of "going concern" goodwill (present value of abnormal earnings (Ohlson, 1995)) and is expected to be positively correlated with GOODWILL.

We capture the extent of expected synergies or expected overpayment resulting from the transaction through TRG_RET_DV, ACQ_RET_DV, ACQ_MTB and INDSAME. We expect a positive association between the target's change in market value upon the acquisition announcement, measuring the amount of synergies captured by the target's shareholders, and GOODWILL. The acquirer's change in market value upon the acquisition announcement has an ambiguous effect on the amount of goodwill. A positive change reflects the amount of synergies expected by the acquirer's shareholders, which should lead to a greater level of goodwill, but a negative change reflects a presumption of overpayment for the target firm, which could also lead to a greater amount of goodwill. As a result, the association between ACQ_RET_DV and GOODWILL could be positive or negative so we make no prediction. We also include in the regression the acquirer's market-to-book ratio (ACQ_MTB), to control for the acquirer's own "going concern" goodwill that could affect the ability to generate synergies with the target. As explained in Shalev et al. (2013), acquirer-target industry proximity (INDSAME) could be positively or negatively associated with GOODWILL. Merging two firms in the same industry is likely to generate more synergies, leading to a greater amount of goodwill (and thus a positive association between INDSAME and GOODWILL), but diversification is more likely to lead to overpayment (Denis et al., 1997; Morck et al., 1990) (and thus a negative correlation between INDSAME and GOODWILL). We also make no prediction for the association between INDSAME and GOODWILL. Finally, we also include DEAL_SIZE since larger deals could be associated with more goodwill.

Expected Goodwill is computed with the predicted values of model (1) and Abnormal Goodwill is the residual of the model, i.e., the difference between the actual amount allocated to goodwill and the amount expected, given the economics of the transaction and market expectations. Therefore Actual Goodwill is made up of Expected Goodwill and Abnormal 
Goodwill. Positive abnormal levels of purchase price allocated to goodwill indicate either that the management overallocated a portion of purchase price to goodwill to increase subsequent earnings, or that investors underestimated the extent of overpayment upon initial announcement of the deal.

\subsection{Investors' reaction to Abnormal Goodwill}

The reaction of investors to Abnormal Goodwill is our main interest. H1 states that investors react negatively to higher amounts of Abnormal Goodwill. The most direct approach to assess the effect of information on changes in investors' expectations about the risk, amount and timing of future cash flows consists in studying the stock price reaction over a short time period surrounding the release of new information, i.e., event studies. Kimbrough (2007) analyzes the association between various characteristics of PPA and cumulative abnormal returns surrounding SEC filings containing the first disclosure of the PPA. To test H1, we examine the association between Actual Goodwill, Expected Goodwill, Abnormal Goodwill and cumulative abnormal returns, controlling for other characteristics of the PPA and the acquisition with model (2):

$$
\begin{aligned}
\text { CAR }_{[-1 ;+i]} & =\alpha_{0}+\alpha_{1} \mathrm{GW}_{\mathrm{i}}+\alpha_{2} \mathrm{SCORE}_{\mathrm{i}}+\alpha_{3} \text { MATERIALITY }_{\mathrm{i}}+\alpha_{4} \mathrm{DISP}_{-} \mathrm{TP}_{\mathrm{i}}+\alpha_{5} \mathrm{FORM}_{\mathrm{i}} \\
& +\varepsilon
\end{aligned}
$$

where for transaction $i$ :

ACQ_CAR $[-1 ;+i]=$ acquirer's cumulative abnormal returns from the day before the first release of the PPA to $+i$ days after the release of the PPA in the SEC filing. Abnormal returns are computed using the market model;

$\mathrm{GW}=$ one of the following three variables:

GOODWILL = goodwill divided by deal value;

ExpGW = Expected Goodwill measured as the predicted value of model (1);

AbGW = Abnormal Goodwill estimated as the residuals of model (1);

SCORE $=$ a self-constructed measure of disclosures about the PPA based on five PPAspecific items from SEC filings. SCORE is the number of disclosed PPA items for a given transaction divided by the maximum possible number of PPA items. We identify the following items: (1) total amount of intangible assets identified separately from goodwill, (2) information about several categories of intangible assets, such as technologies, brands or customer relations, (3) explanation of the reasons for recognizing goodwill, (4) amount of future amortization of intangible assets (or 
estimated useful life), and (5) explanation for recognition or non-recognition of inprocess $\mathrm{R} \& \mathrm{D}$;

MATERIALITY = deal value divided by acquirer's total assets at the year-end prior to the deal announcement;

DISP_TP $=$ highest analyst forecast target price minus lowest analyst forecast target price divided by the mean target price in the month prior to the SEC filing;

FORM $=1$ if the PPA is disclosed in a $10-\mathrm{K}$ filing, and 0 otherwise.

If investors process and use (at least some of) the PPA information content, the estimated coefficient for $\mathrm{AbGW}$ should be significantly different from 0 . We expect a negative estimated coefficient $\alpha_{1}$, as a higher amount of Abnormal Goodwill indicates either that management overallocated purchase price to goodwill to increase future reported earnings, or that the overpayment was underestimated by investors. If model (1) correctly measures the amount of Expected Goodwill, then we predict an insignificant estimated coefficient for ExpGW. Given the above expectations, we predict a negative estimated coefficient for GOODWILL because GOODWILL = ExpGW + AbGW.

We control for disclosures associated with PPA, since Shalev (2009) shows that investors react to the disclosure of information about business combinations, which is subject to management discretion. We also control for the relative size of the acquisition (MATERIALITY), the uncertainty regarding the fundamental value of the acquiring company (DISP_TP), and the type of filing in which the PPA is disclosed. We expect a negative relationship between MATERIALITY and cumulative abnormal returns since larger targets' operations could on average be more difficult to combine with acquirers' operations, and larger acquisitions are associated with larger unexpected negative news. We also control for the ex ante uncertainty about the fundamental value of the acquirer, using target price dispersion in the month prior to the SEC filing to proxy for this uncertainty. The greater the dispersion, the more likely it is that the filing will provide new information (unexpected news) to investors. We make no directional predictions for this control variable, because the unexpected news could be positive or negative. Finally, although the type of report or filing could have an impact on the level of disclosures, we attempt no prediction about the reaction to the type of document in which the PPA is disclosed. 


\subsection{Investors' reaction to Abnormal Goodwill for different types of deal}

To disentangle a reaction to overallocation of purchase price to goodwill from a reaction to a greater-than-expected overpayment, we hypothesize that investors' reaction to Abnormal Goodwill is likely to be stronger in the second case if the acquisition was already considered a Bad Deal when initially announced (H2). To identify Bad Deals we examine acquirers' stock returns upon announcement of the acquisition: negative reactions signal Bad Deals and positive reactions signal Good Deals. If investors react to overallocation of the purchase price to goodwill the reaction is likely to be independent of the type of deals. To test $\mathrm{H} 2$ we estimate the following model:

$$
\begin{aligned}
\text { CAR }_{[-1 ;+i]}= & \alpha_{0}+\alpha_{1} \text { Good_Deal }_{\mathrm{i}}+\alpha_{2} \text { ExpGW }_{\mathrm{i}}+\alpha_{3} \mathrm{AbGW}_{\mathrm{i}}+\alpha_{4} \text { Good_Deal }_{\mathrm{i}}{ }^{*} \mathrm{AbGW}_{\mathrm{i}} \\
& +\alpha_{5} \mathrm{SCORE}_{\mathrm{i}}+\alpha_{6} \text { MATERIALITY }_{\mathrm{i}}+\alpha_{7} \mathrm{DISP}_{-} \mathrm{TP}_{\mathrm{i}}+\alpha_{8} \mathrm{FORM}_{\mathrm{i}}+\varepsilon_{\mathrm{i}}
\end{aligned}
$$

where for transaction $i$ :

Good_Deal $=1$ if the acquirer's stock price increases over the three-day window around announcement of the acquisition, and 0 otherwise;

The other variables are as defined earlier.

Coefficient $\alpha_{3}$ captures the association between Abnormal Goodwill and cumulative abnormal returns for Bad Deals, whereas the sum of $\left(\alpha_{3}+\alpha_{4}\right)$ captures the association between Abnormal Goodwill and stock returns for Good Deals. If investors react more strongly to Abnormal Goodwill for Bad Deals than for Good Deals, $\alpha_{3}$ should be statistically negative and $\alpha_{4}$ statistically positive.

\subsection{Abnormal Goodwill and future impairment}

To examine the information content of Abnormal Goodwill, we test its relationship with the frequency and magnitude of future goodwill impairment. If Abnormal Goodwill captures unexpected overpayment, all else equal, an acquirer that recognizes more Abnormal Goodwill should have a greater probability of booking impairment, and should book more impairment in the future if performance deteriorates. To test $\mathrm{H} 3$ we estimate the following models adapted from (Hayn and Hughes, 2006): 


$$
\begin{aligned}
& \operatorname{Pr}\left(\mathrm{DIMP}_{\mathrm{i},[\mathrm{t}+1 ; \mathrm{t}+2]} \text { or } \mathrm{DIMP}_{\mathrm{i},[\mathrm{t}+1 ; \mathrm{t}+2 ; \mathrm{t}+3]}\right)=\alpha_{0}+\alpha_{1} \mathrm{ExpGW}_{\mathrm{i}, \mathrm{t}}+\alpha_{2} \mathrm{AbGW}_{\mathrm{i}, \mathrm{t}}
\end{aligned}
$$

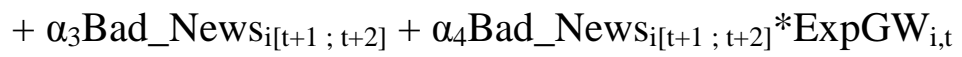

$$
\begin{aligned}
& +\alpha_{5} \text { Bad_News }_{i[t+1 ; t+2]}{ }^{*} \mathrm{AbGW}_{\mathrm{i}, \mathrm{t}}+\alpha_{6} \mathrm{ACQ} \text { _DSALE } \mathrm{i}_{\mathrm{i},[\mathrm{t}+1 ; \mathrm{t}+2]} \\
& +\alpha_{7} \mathrm{ACQ}_{-} \mathrm{ROA}_{\mathrm{i},[\mathrm{t}+1 ; \mathrm{t}+2]}+\alpha_{8} \mathrm{ACQ}_{-} \mathrm{DROA} \mathrm{i}_{\mathrm{i}, \mathrm{t}+1 ; \mathrm{t}+2]}+\alpha_{9} \mathrm{ACQ} \text { BS_GDWL } \mathrm{i}_{\mathrm{i}, \mathrm{t}} \\
& +\alpha_{10} \mathrm{ACQ} \mathrm{MTB}_{\mathrm{i},[\mathrm{t}+1 ; \mathrm{t}+2]}+\alpha_{11} \mathrm{ACQ} \_\mathrm{SIZE} \mathrm{E}_{\mathrm{i},[\mathrm{t}+1 ; \mathrm{t}+2]} \\
& +\alpha_{12} \text { ACQ_LEV } \mathrm{V}_{\mathrm{i},[\mathrm{t}+1 ; \mathrm{t}+2]}+\text { Acquirer industry dummies }+\varepsilon_{\mathrm{i}} \\
& \left.\operatorname{IMPpct}_{\mathrm{i},[t+1 ; t+2 ; t+3]}\right)=\alpha_{0}+\alpha_{1} \operatorname{ExpGW}_{\mathrm{i}, \mathrm{t}}+\alpha_{2} \mathrm{AbGW}_{\mathrm{i}, \mathrm{t}}+\alpha_{3} \mathrm{Bad} \_N e w s_{\mathrm{i}[\mathrm{t}+1 ; \mathrm{t}+2 ; \mathrm{t}+3]} \\
& +\alpha_{4} \text { Bad_News }_{\mathrm{i}[\mathrm{t}+1 ; \mathrm{t}+2 ; \mathrm{t}+3]} * \operatorname{ExpGW}_{\mathrm{i}, \mathrm{t}}+\alpha_{5} \mathrm{Bad} \_N e w s_{\mathrm{i}[\mathrm{t}+1 ; \mathrm{t}+2 ; \mathrm{t}+3]} * \mathrm{AbGW}_{\mathrm{i}, \mathrm{t}} \\
& +\alpha_{6} \text { ACQ_DSALE }_{\mathrm{i},[\mathrm{t}+1 ; \mathrm{t}+2 ; \mathrm{t}+3]}+\alpha_{7} \mathrm{ACQ}_{-} \mathrm{ROA}_{\mathrm{i},[\mathrm{t}+1 ; \mathrm{t}+2 ; \mathrm{t}+3]} \\
& +\alpha_{8} \mathrm{ACQ}_{2} \text { DROA } \mathrm{i}_{,[\mathrm{t}+1 ; \mathrm{t}+2 ; \mathrm{t}+3]}+\alpha_{9} \mathrm{ACQ} \_\mathrm{BS} \_G D W L_{\mathrm{i}, \mathrm{t}} \\
& +\alpha_{10} \text { ACQ_MTB }{ }_{i,[t+1 ; t+2 ; t+3]}+\alpha_{11} \text { ACQ_SIZE }_{\mathrm{i},[\mathrm{t}+1 ; \mathrm{t}+2 ; \mathrm{t}+3]} \\
& +\alpha_{12} \mathrm{ACQ}_{2} \mathrm{LEV}_{\mathrm{i},[\mathrm{t}+1 ; \mathrm{t}+2 ; \mathrm{t}+3]}+\text { Acquirer industry dummies }+\varepsilon_{\mathrm{i}}
\end{aligned}
$$

where for acquirer $i$ :

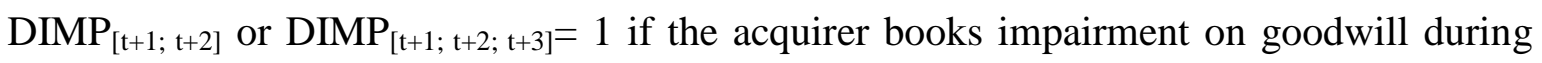
the two years or three years following the acquisition;

IMPpct $_{[t+1 ; t+2 ; t+3]}=$ sum of all goodwill impairment booked in $t+1, t+2$ and $t+3$ after the acquisition divided by total assets in $\mathrm{t}$;

Bad_News $_{[t+1 ; t+2]}=1$ if the acquirer's average stock return over the two years following the acquisition is negative, and 0 otherwise (computed over $t+1$ to $t+3$ if the dependent variable is $\operatorname{DIMP}_{[t+1 ; t+2 ; t+3]}$ or $\left.\operatorname{IMPpct}_{[t+1 ; t+2 ; t+3]}\right)$;

ACQ_DSALE $E_{[t+1 ; t+2]}=$ acquirer's average change in sales during the two years following the acquisition (computed over $t+1$ to $t+3$ if the dependent variable is $\operatorname{DIMP}_{[t+1 ; t+2 ; t+3]}$ or IMPpct $_{[t+1 ; t+2 ; t+3]}$;

ACQ_RET ${ }_{[t+1 ; t+2]}=$ acquirer's average stock returns during the two years following the acquisition (computed over $t+1$ to $t+3$ if the dependent variable is $\operatorname{DIMP}_{[t+1 ; t+2 ; t+3]}$ or IMPpct $_{[t+1 ; t+2 ; t+3]}$;

ACQ_ROA $A_{[t+1 ; t+2]}=$ acquirer's average return on assets (ROA) during the two years following the acquisition (computed over $t+1$ to $t+3$ if the dependent variable is $\operatorname{DIMP}_{[t+1 ; t+2 ; t+3]}$ or IMPpct $\left.[t+1 ; t+2 ; t+3]\right)$;

ACQ_DROA $A_{[t+1 ; t+2]}=$ acquirer's average change in ROA during the two years following the acquisition (computed over $t+1$ to $t+3$ if the dependent variable is $\operatorname{DIMP}_{[t+1 ; t+2 ; t+3]}$ or IMPpct $[t+1 ; t+2 ; t+3])$; 
ACQ_BS_GDWL $=$ acquirer's goodwill divided by total assets at the end of the year after completion of the acquisition;

ACQ_MTB ${ }_{[t+1 ; t+2]}=$ acquirer's average market-to-book ratio during the two years after completion of the acquisition (computed over $t+1$ to $t+3$ if the dependent variable is $\operatorname{DIMP}_{[t+1 ; t+2 ; t+3]}$ or IMPpct $\left.[t+1 ; t+2 ; t+3]\right)$;

ACQ_SIZE $\mathrm{E}_{[t+1 ; t+2]}=$ acquirer's average natural logarithm of total assets during the two years after completion of the acquisition (computed over $t+1$ to $t+3$ if the dependent variable is $\operatorname{DIMP}_{[t+1 ; t+2 ; t+3]}$ or $\left.\operatorname{IMPpct}_{[t+1 ; t+2 ; t+3]}\right)$;

ACQ_LEV $V_{[t+1 ; t+2]}=$ acquirer's average total long-term debt divided by total assets during the two years after completion of the acquisition (computed over $t+1$ to $t+3$ if the dependent variable is $\operatorname{DIMP}_{[t+1 ; t+2 ; t+3]}$ or $\operatorname{IMPpct}_{[t+1 ; t+2 ; t+3]}$ );

The other variables are as defined earlier.

Impairment testing is an accounting mechanism intended to ensure timely loss recognition (André et al., 2014; Kim et al., 2013; Roychowdhury and Martin, 2013), i.e., so that bad news (or losses) regarding earnings is reflected more promptly than good news (or gains) (Basu, 1997). We therefore examine how the level of Abnormal Goodwill affects the probability of booking future goodwill impairment when news is bad. To avoid losing too many observations, we examine impairment booked during the two to three years following completion of the acquisition (although recognition of goodwill impairment could be delayed by more than three years (e.g., Hayn and Hughes, 2006)). ${ }^{11}$

Following Basu (1997), we measure news with stock returns. The coefficients of interest are $\alpha_{2}+\alpha_{5}$ which together capture the effect of Abnormal Goodwill on the probability of goodwill impairment in the future when news is negative (negative stock returns). We expect $\alpha_{2}+\alpha_{5}$ to be positive and significant if Abnormal Goodwill reflects unexpected overpayment, i.e., firms with a greater amount of Abnormal Goodwill are more likely to write down their goodwill and book a larger impairment loss if returns are negative. Expected Goodwill captures expected going concern goodwill, expected synergies and expected overpayment, and could be positively or negatively associated with the frequency and magnitude of future impairment. We therefore make no prediction for $\alpha_{1}+\alpha_{4}$.

\footnotetext{
${ }^{11}$ We collect the total goodwill impairment from Compustat, which might result in a noisy measure of goodwill impairment related to the specific transactions identified in our sample. Nonetheless, if impairment identified in Compustat is unrelated to the transactions in our sample, this is likely to work against our hypothesized results.
} 
We control for various factors affecting the likelihood and magnitude of impairment, i.e., change in sales, stock returns, ROA, change in ROA, acquirer's balance sheet goodwill, acquirer's market-to-book ratio, acquirer size, and acquirer leverage. We expect a negative association between ROA, change in ROA, market-to-book ratio, acquirer size, stock returns and future impairment. We expect a positive association between the level of balance sheet goodwill, leverage and future impairment. We also include industry dummies to control for sector characteristics.

\subsection{Abnormal Goodwill and future change in acquirer performance}

A greater level of Abnormal Goodwill could indicate a Bad Deal and negatively affect firm performance (H4). We therefore compare the performance of the acquirer after the transaction, i.e., the merged entity, to the average performance of the acquirer and target firms as stand-alone entities before the business combination. Specifically, we investigate the effect of Abnormal Goodwill on the difference between the acquirer's future ROA and the assetweighted average ROA of the acquirer and target companies before the transaction. ${ }^{12} \mathrm{We}$ estimate model (6) adapted from (Shalev, 2009):

$$
\begin{aligned}
\Delta \mathrm{ROA}_{\mathrm{i},[\mathrm{t}+1 ; \mathrm{t}+2]}= & \alpha_{0}+\alpha_{1} \operatorname{ExpGW}_{\mathrm{i}, \mathrm{t}}+\alpha_{2} \mathrm{AbGW}_{\mathrm{i}, \mathrm{t}}+\alpha_{3} \mathrm{ACQ}_{-} \mathrm{DSALE} \\
& +\alpha_{\mathrm{i},[\mathrm{t}+1 ; \mathrm{t}+2]} \mathrm{ACQ}_{\mathrm{R}} \mathrm{RET}_{\mathrm{i},[\mathrm{t}+1 ; \mathrm{t}+2]}+\alpha_{5} \mathrm{ACQ}_{-} \mathrm{MTB}_{\mathrm{i},[\mathrm{t}+1 ; \mathrm{t}+2]}+\alpha_{6} \mathrm{ACQ}_{-} \mathrm{SIZE}_{\mathrm{i},[\mathrm{t}+1 ; \mathrm{t}+2]} \\
& +\alpha_{7} \mathrm{ACQ}_{2} \mathrm{ROA}_{\mathrm{i}, \mathrm{t}}+\text { Acquirer industry dummies }+\varepsilon
\end{aligned}
$$

where for acquirer $i$ :

$\Delta \mathrm{ROA}_{[\mathrm{t}+1 ; \mathrm{t}+2]}=$ Acquirer's average ROA in $t+1$ and $t+2$ following the acquisition minus the asset-weighted average of acquirer's and target's ROA in $t-1$;

ACQ_DSALE $[t+1 ; t+2]=$ acquirer's average change in sales during the two years following the acquisition;

ACQ_RET = acquirer's average stock returns during the two years following the acquisition;

ACQ_MTB ${ }_{[t+1 ; t+2]}=$ acquirer's average market-to-book ratio during the two years following the acquisition;

ACQ_SIZE $[t+1 ; t+2]=$ acquirer's average natural logarithm of total assets during the two years after completion of the acquisition;

ACQ_ROA $A_{t}=$ acquirer's return on assets during the year of completion of the acquisition;

\footnotetext{
${ }^{12}$ We thank one reviewer for his/her help with this analysis.
} 
The other variables are as defined earlier.

We use the average ROA in $t+1$ and $t+2$ to allow a reasonable time for the target firm to be fully integrated by the acquirer. The main coefficient of interest is $\alpha_{2}$. We expect a significantly negative estimated coefficient $\alpha_{2}$ as Abnormal Goodwill can be negatively correlated with the quality of acquisitions, and poor acquisitions are likely to reduce acquirers' future performance. Expected Goodwill captures expected synergies and expected overpayment, and could be positively or negatively associated with the change in future performance. Therefore, we make no prediction for ExpGW.

We control for various factors affecting future changes in ROA, i.e., change in sales, stock returns, market-to-book ratio, size and the current level of ROA. We expect a positive association between future change in sales, future stock returns, future market-to-book ratio and change in future operating performance. Following Shalev (2009), we expect a negative association between the current level of ROA and future changes in ROA. We do not attempt any prediction for the association between future size and change in future ROA, because larger firms could be more or less profitable than smaller firms.

\section{Empirical results}

\subsection{Sample selection and description}

Our sample comprises transactions contained in the Thomson One Banker database completed from January 1, 2002 to December 31, 2011 (after the first application of SFAS 141). We require both the target and acquirer to be public companies. We exclude deals below a value of $\$ 100$ million, keeping only economically significant transactions. We also exclude deals in the following three macro industries: Financials, Real estate and Government and agencies. We delete specific transactions such as minority stake purchases, acquisitions of remaining interests, self-tenders, share repurchases, and spinoffs.

SFAS 141 requires firms to disclose their finalized PPA within one year of completion of the acquisition. They may adjust their fair value estimates during that period, as preparing a PPA is complex and time-consuming. Rule 425 of the Securities and Exchange Commission does not require disclosure of the PPA in the merger prospectus. Information disclosed in form $8-\mathrm{K}$ does not usually contain the PPA, and may actually provide only limited factual 
information (as illustrated by form 8-K filed by LSI Logic on April 2, $2007^{13}$ ). In most cases, PPAs are disclosed for the first time in forms 10-Q or 10-K. Therefore, we hand-collect PPA data from SEC filings (forms 10-Q and 10-K), particularly the amount of goodwill resulting from the business combination and PPA-specific disclosures following completion of the acquisition. We also obtain data for dependent and independent variables from Compustat, CRSP and I/B/E/S. Any deals with missing data in Compustat, CRSP, I/B/E/S or SEC filings are deleted, leaving a final sample of 308 business combinations. We winsorize each continuous variable at its first and ninety-ninth percentiles. Panel A of Table 1 provides descriptive statistics for our sampling process.

\section{[Insert Table 1 About Here]}

Panel B of Table 1 provides a description of the transactions per industry. Transactions are clustered in the Information Technology and Healthcare industries (representing respectively $39.9 \%$ and $25.0 \%$ of all transactions), whereas Telecommunication Services and Utilities have the lowest levels of representation (1.9\% each). Panel C shows that our sample is relatively uniformly distributed over the 10 years, with 2007 (2009 and 2011) having the highest (lowest) number of completed acquisitions.

Panel D of Table 1 exhibits descriptive statistics for the variables used in the determinants of expected goodwill. Mean (median) goodwill (GOODWILL) accounts for $52.3 \%(55.6 \%)$ of the purchase price. ${ }^{14}$ Target's R\&D expense has a mean (median) value of $3.5 \%(1.6 \%)$ of the deal value, mean (median) target's advertising expense is $0.5 \%(0.0 \%)$ of deal value. The target's mean (median) balance sheet goodwill is $8.2 \%(1.8 \%)$ of the deal value and other intangibles represent a mean (median) $2.8 \%(0.0 \%)$ of the deal value. The mean (median) target's PPE (tangible assets) has a value of $31.8 \%(12.2 \%)$ of the deal value. The mean (median) target market-to-book ratio is 5.31 (3.71) and the acquirer's mean (median) market-to-book ratio is 3.47 (2.78). The target's mean (median) average sales growth is $22.7 \%(11.3 \%)$ and the target's mean (median) ROA is $8.6 \%(10.8 \%)$. The target's mean (median) change of market value upon announcement of the deal is $15.4 \%$ (14.7\%) of

\footnotetext{
13 “On April 2, 2007, LSI Logic Corporation ("LSI") issued a press release announcing the consummation of the merger of Atlas Acquisition Corp., a wholly owned subsidiary of LSI, with and into Agere Systems Inc. ("Agere") contemplated by the Agreement and Plan of Merger, dated as of December 3, 2006, by and among LSI, Atlas Acquisition Corp. and Agere. A copy of the press release [...]." The document does not provide any information concerning the PPA.

${ }^{14}$ The magnitude of goodwill is comparable to that documented in other studies. Henning et al. (2000), Shalev (2009) and Shalev et al. (2013) respectively report goodwill to be 57\%, 59\% and 59\% of the purchase price on average.
} 
the deal value and the acquirer's mean (median) change of market value upon announcement is $4.1 \%(-2.2 \%)$ of the deal value. $92.5 \%$ of acquisitions are within the same industry.

Panel E of Table 1 presents descriptive statistics for variables used to test investors' reaction to Abnormal Goodwill. Acquirers provide on average only about half of PPAspecific disclosures, as the mean (median) SCORE is only 0.54 (0.60). Panel E shows that our sample is composed of economically significant acquisitions, as the mean (median) deal value represents $55.3 \%(28.3 \%)$ of the acquirers' total assets (MATERIALITY). The mean (median) dispersion of target firms' prices is $43.1 \%$ (35.5\%) of the mean target price. PPAs are disclosed in $10-\mathrm{K}$ forms in $30.2 \%$ of cases and $45.1 \%$ of deals are considered Good Deals since they are received positively (the acquirer's stock price increases when the deal is announced).

We conclude our descriptive analyses with the correlation matrix in Table 1, Panel F. The amount allocated to goodwill (GOODWILL) is significantly negatively correlated with the target firm's R\&D expense and tangible assets, and significantly positively correlated with the target firm's advertising expense, balance sheet goodwill and other intangible assets, target market-to-book ratio and target performance.

\subsection{Results}

\subsubsection{Estimation of Expected Goodwill}

Table 2 presents the estimation results for model (1) estimating the expected level of purchased goodwill consistent with factors affecting: (1) fair value adjustments of the target's existing and new tangible and intangible assets, (2) the target's going concern goodwill, (3) expected synergies between the acquirer and the target firms, and expected overpayment at the time of initial announcement.

\section{[Insert Table 2 About Here]}

Results indicate that target firms' $R \& D$ expense is negatively associated with the amount of the purchase price allocated to goodwill (significant at less than 1\%, two-sided). The amount of goodwill recognized in the target's balance sheet is positively associated with the level of goodwill resulting from the PPA (significant at less than 1\%, two-sided). Conversely, the percentage of tangible assets is negatively associated with the amount allocated to goodwill (significant at less than 10\%, two-sided). The target's market-to-book ratio is 
positively associated with the amount of recognized goodwill (significant at less than 5\%, two-sided).

Overall, economic factors explain $32.0 \%$ of the amount allocated to goodwill (see $\mathrm{R}^{2}$ ). Model (1) captures the amount of Expected Goodwill, i.e. goodwill that is expected to be recognized considering the economic factors underlying the acquisition known at the time of initial announcement. Next, we compute Abnormal Goodwill, defined as the residuals from model (1). Table 2, Panel B shows descriptive statistics for the fitted values (ExpGW) and estimated residuals of model (1) (AbGW). By construction, Abnormal Goodwill has a mean value of 0 and ranges between $-66.7 \%$ and $+58.0 \%$ of the deal value. The standard deviation from expected goodwill is relatively large, at $21.5 \%$ of the deal value.

\subsubsection{Investors' reaction to Abnormal Goodwill}

H1 expects investors to react negatively (positively) to higher (lower) levels of Abnormal Goodwill. Table 3 presents the estimation results of model (2) that examines investors' reaction to Total Goodwill, Expected Goodwill and Abnormal Goodwill surrounding the disclosure of PPAs.

\section{[Insert Table 3 About Here]}

Table 3 shows a negative association between the amount of goodwill identified in the PPA and cumulative abnormal returns computed over the six-day window around the disclosure of PPA in SEC filings (the estimated coefficient for GOODWILL is significant at less than $5 \%$, two-sided). ${ }^{15}$ An increase of one standard deviation in GOODWILL would decrease cumulative abnormal returns by 58 basis points. ${ }^{16}$ This reaction is driven by Abnormal Goodwill, as Table 3 also shows that investors react negatively to the amount of Abnormal Goodwill (the estimated coefficient for $\mathrm{AbGW}$ is negative and significant at less than 5\%, two-sided). An increase of one standard deviation in AbGW would decrease cumulative abnormal return by 53 basis points. There is no reaction to the level of Expected Goodwill, consistent with model (1) correctly measuring the market expectation of goodwill resulting from the transaction at the time of announcement (the estimated coefficient for ExpGW is non-significant). Overall, this indicates that investors react to the information

\footnotetext{
${ }^{15}$ Results are qualitatively similar if we compute cumulative abnormal returns over five-day and seven-day windows.

${ }^{16}$ The standardized coefficient estimated for GOODWILL is -0.1188 (untabulated); therefore the effect of an increase of one standard deviation in GOODWILL on CAR $=-0.1188 * 0.049$ (standard deviation of $\mathrm{CAR}_{[-1 ;+4]}$, see Table 1, Panel E) $=-0.0058$.
} 
content of PPA, and in particular that they react negatively to unexpectedly high amounts of purchase price allocated to goodwill.

This is consistent with higher Abnormal Goodwill signaling either that management overallocated purchase price to increase future earnings (Shalev et al., 2013) or that the extent of overpayment was underestimated by market participants upon initial announcement of the acquisition. Investors' reaction to PPA is consistent with the efficient market hypothesis, as stock prices react to the release of new information. This result also supports the joint FASB and IASB position regarding the usefulness of PPA for market participants.

Disclosures about PPA are not associated with cumulative abnormal returns. As expected, materiality is negatively associated with cumulative abnormal returns subsequent to the disclosure of PPA (significant at less than 5\%, two-sided).

\subsubsection{Investors' reaction to Abnormal Goodwill and types of deal}

To distinguish between a reaction to an overallocation of purchase price to goodwill and a reaction to the extent of overpayment, we examine the association between Abnormal Goodwill and cumulative abnormal returns in relation to the type of deal, i.e., for Good Deals, defined as deals that received a positive reaction from investors upon announcement vs. Bad deals, defined as deals that received a negative reaction from investors upon announcement (H2). We hypothesize that for Bad Deals, investors react more strongly to Abnormal Goodwill if it signals information about the extent of overpayment. Table 4 presents an analysis of the differing information content of Abnormal Goodwill for the two types of deal.

[Insert Table 4 About Here]

Panel A of Table 4 provides descriptive statistics for the mean seven-day cumulative abnormal returns for both types of deal and positive vs. negative levels of Abnormal Goodwill. The lowest cumulative abnormal returns appear to occur in the case of positive Abnormal Goodwill for deals that were negatively received by investors when initially announced ( -182 basis points when $\mathrm{AbGW}>0$ and $\mathrm{Bad}$ Deal $=1$ vs. -17 to -51 basis points for the three other cases).

Panel B of Table 4 presents the estimation results of model (3) over three different time windows. Coefficient $\alpha_{3}$ captures the effect of Abnormal Goodwill on cumulative abnormal returns for Bad Deals whereas coefficient $\alpha_{4}$ measures the incremental effect for Good Deals. Results show that Abnormal Goodwill is negatively associated with cumulative abnormal 
returns for Bad Deals (significant at less than 1\%, two-sided). An increase of one standard deviation in AbGW would be associated with a decrease in cumulative abnormal returns ranging from 89 to 101 basis points for Bad Deals over our three time windows. The difference in reaction for Good Deals vs. Bad Deals is significant in all three event windows (the estimated coefficient $\alpha_{4}$ is positive and significant at less than 10\%, two-sided). Overall, our results indicate that investors revise their expectations about the extent of overpayment because they react more strongly to Abnormal Goodwill for acquisitions that were already negatively perceived when initially announced.

\subsubsection{Abnormal Goodwill and future impairment}

We test the ability of Abnormal Goodwill resulting from PPA to reflect the future performance of business combinations. The empirical results reported above indicate that Abnormal Goodwill captures the extent of unexpected overpayment, therefore the greater the amount of Abnormal Goodwill, the greater the likelihood and magnitude of future goodwill impairment when performance deteriorates (H3). Panel A of Table 5 presents descriptive statistics for recognition of impairment during the two to three years following completion of acquisitions.

\section{[Insert Table 5 About Here]}

Panel A of Table 5 shows that during the two years following completion of acquisitions, $16.3 \%$ of acquirers booked goodwill impairment at least once $\left(\operatorname{DIMP}_{[t+1 ; t+2]}\right)$. In the three years following completion of acquisitions, the frequency of goodwill impairment is $25.0 \%{ }^{17}$ The magnitude of the sum of all goodwill impairment booked during $t+1$ to $t+3$ is $3.5 \%$ of total assets measured in the year of completion of acquisitions. Panel B presents evidence that the frequency and magnitude of future goodwill impairment increases as Abnormal Goodwill increases. Over the two (three) years following completion of acquisitions, the frequency of goodwill impairment for acquirers with negative Abnormal Goodwill is $14.47 \%$ (22.53\%) vs. $18.24 \%(27.53 \%)$ for acquirers with positive Abnormal Goodwill. This difference is economically significant, suggesting that acquirers with positive levels of Abnormal Goodwill are $26 \%(22 \%)$ more likely to book goodwill impairment within two (three) years than acquirers with negative Abnormal Goodwill. ${ }^{18}$ Panel B also shows that acquirers that exhibit

\footnotetext{
${ }^{17}$ We lose 37 observations by extending the analysis to year $t+3$.

${ }^{18} 26 \%=18.24 / 14.47-1$ and $22 \%=27.53 / 22.53-1$.
} 
positive Abnormal Goodwill book larger amounts of goodwill impairment after completion of acquisitions ( $0.92 \%$ more of total assets over $t+1$ to $t+3)$.

Estimation results of model (4) are presented in Panel C. The sum of coefficients $\alpha_{2}$ and $\alpha_{5}$ captures the effect of the level of Abnormal Goodwill on the probability of booking goodwill impairment when there is negative news about the acquirer (negative stock returns) (Bad_News $=1)$. For impairment booked over the two years after completion of acquisition, the sum of $\alpha_{2}$ and $\alpha_{5}$ is positive and significantly different from 0 (at less than 10\%, twosided). For impairment booked over the three years after completion of acquisitions, the sum of $\alpha_{2}$ and $\alpha_{5}$ is also positive and significant (at less than 5\%, two-sided). Acquirers with larger amounts of Abnormal Goodwill are more likely to book goodwill impairment over the three years following completion of acquisitions.

The level of Expected Goodwill, which captures the expected going concern goodwill, expected synergies and expected overpayment, exhibit no significant effect on the frequency of future goodwill impairment. As expected, average change in sales, average stock returns, and average ROA are negatively associated with the likelihood of impairment. The amount of goodwill in the balance sheet and financial leverage are positively associated with the likelihood of subsequent goodwill impairment.

Panel D reports the estimation results of model (5) and shows that Abnormal Goodwill is also positively associated with the magnitude of goodwill impairment booked over the three years following completion of the acquisition (the sum of $\alpha_{2}$ and $\alpha_{5}$ is positive and significant at less than 5\%, two-sided). Size and ROA are negatively associated with the magnitude of impairment, and the levels of goodwill and leverage are positively associated with the magnitude of future impairment. Expected Goodwill is also unrelated to the magnitude of future goodwill impairment.

\subsubsection{Abnormal Goodwill and acquirer's future performance}

To corroborate our findings, we examine whether the level of Abnormal Goodwill explains the acquirer's future performance in Table 6.

\section{[Insert Table 6 About Here]}

Panel A presents the change in performance, measured by the difference between the average ROA over the two years following the acquisition and the asset-weighted average ROA of the acquirer and target firms before the transaction based on quartiles of Abnormal 
Goodwill. It shows that the higher the level of Abnormal Goodwill resulting from the PPA, the lower the change in future performance $(+2.8 \%$ for the quartile with the lowest level of Abnormal Goodwill vs. $-0.8 \%$ for the quartile with the highest level of Abnormal Goodwill). We test H4 with model (6). Panel B presents the estimation results of the regression.

Panel B of Table 6 indicates that Abnormal Goodwill is negatively associated with the average change in ROA over the two years after the acquisition (significant at less than 5\%, two-sided). Post-acquisition performance decreases as Abnormal Goodwill increases. These results corroborate the idea that Abnormal Goodwill is informative about the quality of acquisitions. Expected Goodwill has no significant effect on the change in ROA. Change in sales, stock returns and size are positively associated with future change in ROA. The acquirer's current ROA is negatively associated with the future change in ROA, similar to Shalev (2009).

\section{Robustness tests}

The reported effect between Abnormal Goodwill and cumulative abnormal goodwill could be coincidental. There is a possibility that the relationship between Abnormal Goodwill and abnormal returns might actually be driven by more general disclosure effects, i.e., investors reacting to overall disclosure quality, not only to Abnormal Goodwill resulting from PPA in SEC filings. If Abnormal Goodwill is correlated with the overall quality of quarterly and annual reports, the observed association between Abnormal Goodwill and stock returns might be explained by that reporting quality. We rule out this alternative "overall disclosure effect" explanation for an association between Abnormal Goodwill and stock reaction by examining the relationship surrounding another SEC filing in which no PPA is disclosed. If Abnormal Goodwill is correlated with the overall quality of quarterly and annual reports, it is likely also to be correlated with the quality of other previous reports, since the quality of financial reporting is unlikely to change drastically over time, i.e., firms exhibiting poor financial reporting are unlikely to become very transparent in a short period of time, and vice versa. We find no evidence of a reaction to Abnormal Goodwill for cumulative abnormal returns computed around SEC filings in which no PPA is disclosed.

SFAS 141 was revised in 2007, and SFAS 141R introduced a number of different rules applicable for acquisitions completed since late 2008 (e.g., acquisition cost, contingent consideration, and goodwill recorded in step-acquisitions). To test the sensitivity of our results to the change in the standard, we exclude acquisitions completed after December 31, 
2008 and re-run all our models. Results based on pre-SFAS 141R acquisitions only are qualitatively similar. ${ }^{19}$

\section{Conclusion}

Purchase price allocations (PPAs) following business combinations are required by accounting standards (SFAS 141 in the U.S., and IFRS 3 in an international setting) and involve extensive recognition of intangible assets separately from residual goodwill. Standard-setters argue that disclosing the nature and amount of acquired assets provides useful information for investors to assess the amount, risk and timing of future cash flows. Yet this position is challenged by some academics (e.g., Garten, 2001; Kanodia et al., 2004; Penman, 2009; Skinner, 2008) and financial report users (e.g., CRUF, 2008) on two grounds. First, concerns are expressed as to the usefulness of separate identification and valuation of intangible assets. Second, there are greater incentives for earnings management behaviors in separate recognition of intangible assets that relies on subjective fair value estimates, and this can adversely affect financial reporting quality.

This paper investigates the extent to which investors react to the information content of PPAs, and whether PPAs required by standard-setters improve financial statement usefulness for investors making economic decisions with regard to capital allocation. To address this question, we examine the reaction to allocation of an abnormal amount of the purchase price to goodwill, leading to Abnormal Goodwill defined as the difference between actual goodwill and Expected Goodwill based on the investors' expectation upon the initial announcement of the transaction, using a hand-collected sample of 308 economically significant U.S. business combinations completed over the period 2002-2011.

We provide evidence that market participants react negatively to Abnormal Goodwill resulting from PPA when it is disclosed in SEC filings. Our results suggest that PPA has useful information content for stock valuation. The negative reaction to higher levels of Abnormal Goodwill appears to be driven by investors revising their assessment of the extent of overpayment, rather than by a reaction to overallocation of purchase price to goodwill. We also present evidence that Abnormal Goodwill provides information about the quality of acquisitions. We show that the frequency and magnitude of future goodwill impairment increases as Abnormal Goodwill increases, and that the change in future ROA decreases as Abnormal Goodwill increases.

\footnotetext{
${ }^{19}$ Results of these tests are available upon request.
} 
This paper contributes to the literature in several ways. First, it provides insights of interest to financial report issuers and standard-setters into the implications of requiring PPAs. Investors analyze the quality of PPAs and react to their information content. We show that PPAs are informative for investors, supporting the US and international standard-setters' position. Second, our analysis also demonstrates what type of information is conveyed by Abnormal Goodwill. We show that the level of goodwill resulting from PPA is informative about the quality of the acquisition and is an early indicator of future impairment and change in performance.

There are several limitations to this study, as we measure the quality of PPA based on a single key accounting item: the amount of recognized goodwill. Other measures or methodologies could also be relevant, although we argue that goodwill is decisive in the overall informativeness of PPA. Further potentially interesting questions for research would be how acquirers justify the amount recognized as goodwill, particularly in cases where an abnormal amount of the purchase price appears to be allocated to goodwill, and whether additional disclosures in such a context could help investors identify potential overpayment. 


\section{References}

AICPA, 1970a. Accounting Principles Board (APB) No. 16: Business Combinations. American Institute of Certified Public Accountants.

AICPA, 1970b. Accounting Principles Board (APB) No. 17: Intangible Assets. American Institute of Certified Public Accountants.

André, P., Filip, A., Paugam, L., 2014. Effect of Mandatory IFRS Adoption on Conditional Conservatism in Europe. Journal of Business Finance \& Accounting Forthcoming.

Ball, R., 2006. International Financial Reporting Standards (IFRS): pros and cons for investors. Accounting \& Business Research 36, 5-27.

Basu, S., 1997. The conservatism principle and the asymmetric timeliness of earnings. Journal of Accounting \& Economics 24, 3-37.

Basu, S., Waymire, G., 2008. Has the importance of intangibles really grown? And if so, why? Accounting \& Business Research 38, 171-190.

Browning, B., 1997. Maximizing R\&D Write-offs to reduce goodwill. Mergers and Acquisitions 32, 29-32.

CRUF, 2008. Corporate Reporting Users' Forum Presentation, April 22, 2008 FASB/IASB Joint Board Meeting.

Denis, D.J., Denis, D.K., Sarin, A., 1997. Agency Problems, Equity Ownership, and Corporate Diversification. The Journal of Finance 52, 135-160.

Dunne, K.M., 1990. An Empirical Analysis of Management's Choice of Accounting Treatment for Business Combinations. Journal of Accounting \& Public Policy 9, 111133.

FASB, 2001. Statement of Financial Accounting Standards (SFAS) No. 141: Business Combinations. Financial Accounting Standards Board, Norwalk, CT.

Francis, J., Hanna, J.D., Vincent, L., 1996. Causes and Effects of Discretionary Asset WriteOffs. Journal of Accounting Research 34, 117-134.

Garten, J.E., 2001. Strengthening Financial Markets: Do Investors Have the Information They Need? Report of an SEC-Inspired Task Force.

Gu, F., Lev, B., 2011. Overpriced Shares, Ill-Advised Acquisitions, and Goodwill Impairment. Accounting Review 86, 1995-2022.

Hayn, C., Hughes, P.J., 2006. Leading Indicators of Goodwill Impairment. Journal of Accounting, Auditing \& Finance 21, 223-265.

Henning, S.L., Lewis, B.L., Shaw, W.H., 2000. Valuation of the Components of Purchased Goodwill. Journal of Accounting Research 38, 375-386.

Hirschey, M., Richardson, V.J., 2002. Information content of accounting goodwill numbers. Journal of Accounting \& Public Policy 21, 173-191.

Holthausen, R.W., Watts, R.L., 2001. The relevance of the value-relevance literature for financial accounting standard setting. Journal of Accounting \& Economics 31, 3-75.

Hopkins, P.E., Houston, R.W., Peters, M.F., 2000. Purchase, Pooling, and Equity Analysts' Valuation Judgments. Accounting Review 75, 257.

IASB, 2004. International Reporting Financial Standard (IFRS) No. 3: Business combinations. IASC Foundation Publications Department, London.

IASB, 2008. International Reporting Financial Standard (IFRS) No. 3: Business combinations - revised, IASC Foundation Publications Department, London.

Jenkins, H.W.J., 1999. Business World: Mean Old FASB: Forcing Us to Think, The Wall Street Journal.

Jennings, R., Robinson, J., Thompson Ii, R.B., Duvall, L., 1996. The Relation Between Accounting Goodwill Numbers and Equity Values. Journal of Business Finance \& Accounting 23, 513-533. 
Johnson, L.T., Petrone, K.R., 1998. Is goodwill an asset? Accounting Horizons 12, 293-303.

Kanodia, C., Sapra, H., Venugopalan, R., 2004. Should Intangibles Be Measured: What Are the Economic Trade-Offs? Journal of Accounting Research 42, 89-120.

Kim, S., Lee, C., Yoon, S.W., 2013. Goodwill accounting and asymmetric timeliness of earnings. Review of Accounting and Finance 12, 112-129.

Kimbrough, M.D., 2007. Do investors rely on purchase price allocation disclosures?, Working Paper Harvard Business School

Lee, C., 2011. The effect of SFAS 142 on the ability of goodwill to predict future cash flows. Journal of Accounting and Public Policy 30, 236-255.

Li, K.K., Sloan, R.G., 2014. Has Goodwill Accounting Gone Bad?, Working Paper, 42 p.

Maines, L.A., Bartov, E., Fairfield, P.M., Hirst, D.E., Iannaconi, T.A., Mallett, R., Schrand, C.M., Skinner, D.J., Vincent, L., 2003. Implications of Accounting Research for the FASB's Initiatives on Disclosure of Information about Intangible Assets. Accounting Horizons 17, 175-185.

McGoldrick, B., 1997. Goodwill games. Institutional Investor 31, 145-149.

Morck, R., Shleifer, A., Vishny, R.W., 1990. Do Managerial Objectives Drive Bad Acquisitions? Journal of Finance 45, 31-48.

Ohlson, J.A., 1995. Earnings, Book Values, and Dividends in Equity Valuation. Contemporary Accounting Research 11, 661-687.

Penman, S.H., 2009. Accounting for Intangible Assets: There is Also an Income Statement. Abacus 45, 358-371.

Ramanna, K., 2008. The implications of unverifiable fair-value accounting: Evidence from the political economy of goodwill accounting. Journal of Accounting and Economics 45, 253-281.

Ramanna, K., Watts, R., 2012. Evidence on the use of unverifiable estimates in required goodwill impairment. Review of Accounting Studies 17, 749-780.

Roychowdhury, S., Martin, X., 2013. Understanding discretion in conservatism: An alternative viewpoint. Journal of Accounting \& Economics 56, 134-146.

Shalev, R., 2009. The Information Content of Business Combination Disclosure Level. The Accounting Review 84, 239-270.

Shalev, R., Zhang, I.X., Zhang, Y., 2013. CEO Compensation and Fair Value Accounting: Evidence from Purchase Price Allocation. Journal of Accounting Research 51, 819-854.

Skinner, D.J., 2008. Accounting for intangibles - a critical review of policy recommendations. Accounting \& Business Research 38, 191-204.

Vincent, L., 1997. Equity valuation implications of purchase versus pooling accounting. Journal of Financial Statement Analysis 2, 5-15.

Watts, R.L., 2003. Conservatism in Accounting Part I: Explanations and Implications. Accounting Horizons 17, 207-221.

Zanoni, A.B., 2009. Accounting for Goodwill. Routledge/Taylor \& Francis, New York.

Zhang, I., Zhang, Y., 2014. Accounting discretion and purchase price allocation after acquisitions, Working paper. 


\section{Figure 1}

Timeline of a typical acquisition and empirical strategy

Obtaining Acquisition Approvals

(e.g., Regulatory)

Completion of PPA

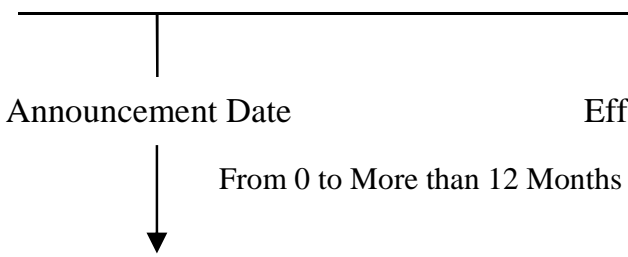

Effective Date

Disclosure of PPA

Estimation of Expected $G W$

depends on:

1. Expected revaluations of assets

2. Expected newly identified assets

3. Expected synergies

4. Expected overpayment

This figure is adapted from Shalev et al. (2013) and summarizes the timeline of a typical acquisition. The timeframes are only an approximation. An acquisition could be announced and consummated immediately, or take a long time. Announcement and consummation could occur in two different fiscal years. GW = goodwill, $\mathrm{PP}=$ purchase price, $\mathrm{AbGW}=$ abnormal (unexpected) goodwill. 


\section{Table 1}

Descriptive statistics

Panel A: Sample selection

\begin{tabular}{lr}
\hline & \# of remaining deals \\
\cline { 2 - 2 } Acquisition of public firms completed between 2002 and 2011 & \\
with a deal value $>\$ 100$ million & 1,058 \\
Excluding financial and regulated sectors & 675 \\
Excluding missing variables from reports or databases & 308 \\
\hline Final sample & 308 \\
\hline
\end{tabular}

The sample is composed of deals with a minimum value of $\$ 100$ million completed between January 2002 and December 2011, excluding financial and regulated sectors (i.e., Thomson Financial macro industries Financials, Real estate and Government and agencies). Target and acquiring firms are both US public companies. Firms with missing data in $10-\mathrm{Q} / \mathrm{K}$, Compustat, CRSP, or I/B/E/S are excluded from the sample.

Panel B: Number of deals per industry

\begin{tabular}{lrr}
\hline GICS Sectors & \# of deals & \multicolumn{1}{c}{$\%$} \\
\hline Energy & 33 & $10.7 \%$ \\
Materials & 9 & $2.9 \%$ \\
Industrials & 24 & $7.8 \%$ \\
Consumer Discretionary & 21 & $6.8 \%$ \\
Consumer Staples & 9 & $2.9 \%$ \\
Health Care & 77 & $25.0 \%$ \\
Information Technology & 123 & $39.9 \%$ \\
Telecommunication Services & 6 & $1.9 \%$ \\
Utilities & 6 & $1.9 \%$ \\
\hline Total & 308 & $100.0 \%$ \\
\hline
\end{tabular}

Panel B presents the number of deals, grouped according to the Global Industry Classification Standard (GICS) of target firms. 
Panel C: Number of deals per year

\begin{tabular}{crr}
\hline Year & \# of deals & \multicolumn{1}{c}{$\%$} \\
\hline 2002 & 28 & $9.1 \%$ \\
2003 & 26 & $8.4 \%$ \\
2004 & 28 & $9.1 \%$ \\
2005 & 38 & $12.3 \%$ \\
2006 & 40 & $13.0 \%$ \\
2007 & 49 & $15.9 \%$ \\
2008 & 25 & $8.1 \%$ \\
2009 & 17 & $5.5 \%$ \\
2010 & 40 & $13.0 \%$ \\
2011 & 17 & $5.5 \%$ \\
\hline Total & 308 & $100.0 \%$ \\
\hline
\end{tabular}


Panel D: Main variables - Determinants of goodwill

\begin{tabular}{lrrrrrr}
\hline & N & Mean & St. Dev & 1st Q. & Median & 3rd. Q \\
\cline { 2 - 7 } GOODWILL & 308 & 0.523 & 0.260 & 0.325 & 0.556 & 0.707 \\
TRG_RD & 308 & 0.035 & 0.050 & 0.000 & 0.016 & 0.048 \\
TRG_AD & 308 & 0.005 & 0.014 & 0.000 & 0.000 & 0.002 \\
TRG_BS_GDWL & 308 & 0.082 & 0.151 & 0.000 & 0.018 & 0.101 \\
TRG_BS_INTAN & 308 & 0.028 & 0.058 & 0.000 & 0.003 & 0.024 \\
TRG_PPE & 308 & 0.318 & 0.490 & 0.046 & 0.122 & 0.373 \\
TRG_MTB & 308 & 5.308 & 8.129 & 2.276 & 3.709 & 6.382 \\
TRG_SAL_GRO & 308 & 0.227 & 0.407 & 0.017 & 0.113 & 0.291 \\
TRG_ROA & 308 & 0.086 & 0.214 & 0.023 & 0.108 & 0.196 \\
ACQ_MTB & 308 & 3.468 & 2.730 & 1.753 & 2.778 & 4.418 \\
TRG_RET_DV & 308 & 0.154 & 0.121 & 0.081 & 0.147 & 0.232 \\
ACQ_RET_DV & 308 & 0.041 & 0.737 & -0.184 & -0.022 & 0.176 \\
INDSAME & 308 & 0.925 & 0.263 & 1.000 & 1.000 & 1.000 \\
DEAL_SIZE & 308 & 6.737 & 1.325 & 5.615 & 6.669 & 7.654 \\
\hline
\end{tabular}

GOODWILL $=$ Goodwill divided by deal value. TRG_RD $=$ Target's R\&D expense over the year before the deal announcement divided by deal value. TRG_AD = Target's advertising expense over the year before the deal announcement divided by deal value. TRG_BS_GDWL = Target's preacquisition goodwill at the year-end prior to the deal announcement divided by deal value. TRG_BS_INTAN = Target's pre-acquisition other intangible assets at the year-end prior to the deal announcement divided by deal value. TRG_PPE = Target's gross property plant $\&$ equipment at the year-end prior to the deal announcement divided by deal value. TRG_MTB = Target's market-to-book ratio at the year-end prior to the deal announcement. TRG_SAL_GRO = Target's average sales growth over the two years before the deal announcement year. TRG_ROA = Target's EBITDA over the year before the deal announcement divided by total assets at the beginning of the year. ACQ_MTB = Acquirer's market-to-book ratio. TRG_RET_DV = Target's dollar amount of stock returns over the three-day window around the announcement of the acquisition divided by deal value. ACQ_RET_DV $=$ Acquirer's dollar amount of stock returns over the three-day window around the announcement of the acquisition divided by deal value. INDSAME $=1$ if the acquirer and the target are from the same GICS sector, and 0 otherwise. DEAL_SIZE = natural logarithm of deal value. 
Panel E: Second stage variables

\begin{tabular}{lrrrrrr}
\hline & $\mathrm{N}$ & \multicolumn{1}{c}{ Mean } & St. Dev & \multicolumn{1}{c}{ st Q. } & Median & 3rd Q. \\
\cline { 2 - 6 } ACQ_CAR $_{[-1 ;+3]}$ & 308 & -0.007 & 0.045 & -0.030 & -0.006 & 0.016 \\
ACQ_CAR $_{[-1 ;+4]}$ & 308 & -0.008 & 0.049 & -0.035 & -0.009 & 0.016 \\
ACQ_CAR & 308 & -0.009 & 0.051 & -0.036 & -0.007 & 0.019 \\
SCORE & 308 & 0.548 & 0.269 & 0.400 & 0.600 & 0.800 \\
MATERIALITY & 308 & 0.553 & 0.725 & 0.114 & 0.287 & 0.693 \\
DISP_TP & 308 & 0.431 & 0.307 & 0.239 & 0.355 & 0.542 \\
FORM & 308 & 0.302 & 0.460 & 0.000 & 0.000 & 1.000 \\
Good_Deal & 308 & 0.451 & 0.498 & 0.000 & 0.000 & 1.000 \\
\hline
\end{tabular}

ACQ_CAR ${ }_{[-1 ;+i]}=$ Acquirer's cumulative abnormal returns computed from the day before the first release of the PPA to $+i$ days after the release of the PPA in the SEC filing. Abnormal returns are computed with the market model. SCORE $=$ Self-constructed measure of disclosures provided about the PPA. MATERIALITY = Deal value divided by acquirer's total assets at the year-end prior to the deal announcement. DISP_TP $=$ highest analyst forecast target price minus lowest analyst forecast target price divided by the mean target price in the month prior to the SEC filing. FORM $=1$ if the PPA is disclosed in a Form $10-\mathrm{K}$ and 0 otherwise. Good_Deal $=1$ if the acquirer's stock price increases over the three-day window around the announcement of the acquisition, and 0 otherwise. 
Panel F: Pearson correlation matrix

\begin{tabular}{|c|c|c|c|c|c|c|c|c|c|c|c|c|c|c|c|c|}
\hline & & 1 & 2 & 3 & 4 & 5 & 6 & 7 & 8 & 9 & 10 & 11 & 12 & 13 & 14 & 15 \\
\hline 1 & GOODWILL & 1 & & & & & & & & & & & & & & \\
\hline 2 & TRG_RD & $-0.10^{*}$ & 1 & & & & & & & & & & & & & \\
\hline 3 & TRG_AD & $0.10^{*}$ & -0.02 & 1 & & & & & & & & & & & & \\
\hline 4 & TRG_BS_GDWL & $0.30 * * *$ & $0.10^{*}$ & $0.13 * *$ & 1 & & & & & & & & & & & \\
\hline 5 & TRG_BS_INTAN & $0.16 * * *$ & $0.12 * *$ & $0.17 * * *$ & $0.39 * * *$ & 1 & & & & & & & & & & \\
\hline 6 & TRG_PPE & $-0.13 * *$ & $-0.13 * *$ & $0.23 * * *$ & $0.11 *$ & $0.10^{*}$ & 1 & & & & & & & & & \\
\hline 7 & TRG_MTB & $0.13 * *$ & -0.04 & -0.06 & $-0.15 * * *$ & $-0.11^{*}$ & $-0.18 * * *$ & 1 & & & & & & & & \\
\hline 8 & TRG_SAL_GRO & -0.08 & $-0.09 *$ & $-0.14 * *$ & $-0.14 * *$ & -0.09 & $-0.11 * *$ & 0.08 & 1 & & & & & & & \\
\hline 9 & TRG_ROA & $0.12 * *$ & $-0.39 * * *$ & 0.05 & 0.06 & 0.05 & $0.17 * * *$ & $-0.10^{*}$ & -0.09 & 1 & & & & & & \\
\hline 10 & ACQ_MTB & -0.03 & $0.12 * *$ & $-0.11 *$ & $-0.14 * *$ & -0.03 & $-0.24 * * *$ & $0.13 * *$ & $0.15 * * *$ & $-0.23 * * *$ & 1 & & & & & \\
\hline 11 & TRG_RET_DV & -0.05 & $0.20 * * *$ & $-0.11 *$ & -0.08 & -0.02 & $-0.23 * * *$ & -0.04 & 0.05 & $-0.16 * * *$ & $0.13 * *$ & 1 & & & & \\
\hline 12 & ACQ_RET_DV & 0.05 & 0.09 & 0.01 & -0.02 & 0.07 & 0.00 & 0.01 & 0.06 & $-0.15 * * *$ & 0.06 & 0.06 & 1 & & & \\
\hline 13 & INDSAME & -0.03 & 0.09 & -0.03 & -0.01 & -0.02 & -0.08 & -0.04 & $0.10^{*}$ & -0.03 & $0.11 *$ & 0.07 & 0 & 1 & & \\
\hline 14 & Good_Deal & -0.04 & 0.08 & 0.07 & 0.04 & $0.11 * *$ & 0.05 & -0.08 & 0.01 & -0.08 & -0.04 & $0.15 * * *$ & $0.54 * * *$ & -0.09 & 1 & \\
\hline 15 & DEAL_SIZE & -0.06 & $-0.37 * * *$ & 0.06 & 0.01 & -0.03 & $0.13 * *$ & 0.09 & -0.04 & $0.28 * * *$ & 0.01 & $-0.21 * * *$ & $-0.19 * * *$ & -0.06 & $-0.18 * * *$ & 1 \\
\hline
\end{tabular}

$* * *, * *$, and $*$ denote significance (two-tailed) at the $0.01,0.05$, and 0.10 levels, respectively.

GOODWILL = Goodwill divided by deal value. TRG_RD = Target's R\&D expense over the year before the deal announcement divided by deal value. TRG_AD = Target's advertising expense over the year before the deal announcement divided by deal value. TRG_BS_GDWL $=$ Target's pre-acquisition goodwill at the year-end prior to the deal announcement divided by deal value. TRG_BS_INTAN = Target's pre-acquisition other intangible assets at the yearend prior to the deal announcement divided by deal value. TRG_PPE $=$ Target's gross property plant $\&$ equipment at the year-end prior to the deal announcement divided by deal value. TRG_MTB = Target's market-to-book ratio at the year-end prior to the deal announcement. TRG_SAL_GRO = Target's average sales growth over the two years before the deal announcement year. TRG_ROA = Target's EBITDA over the year before the deal announcement divided by total assets at the beginning of the year. ACQ_MTB = Acquirer's market-to-book ratio. TRG_RET_DV = Target's dollar amount of stock returns over the three-day window around the announcement of the acquisition divided by deal value. ACQ_RET_DV = Acquirer's dollar amount of stock returns over the three-day window around the announcement of the acquisition divided by deal value. INDSAME $=1$ if the acquirer and the target are from the same GICS sector, and 0 otherwise. DEAL_SIZE = natural logarithm of deal value. 


\section{Table 2}

Panel A: Determinants of expected goodwill

$$
\begin{aligned}
& \text { GOODWILL }{ }_{i}=\alpha_{0}+\alpha_{1} \text { TRG_RD }{ }_{i}+\alpha_{2} \text { TRG_AD }_{\mathrm{i}}+\alpha_{3} \text { TRG_BS_GDWL }{ }_{\mathrm{i}}+\alpha_{4} \text { TRG_BS_INTAN } \mathrm{i} \\
& +\alpha_{5} \text { TRG_PPE }_{\mathrm{i}}+\alpha_{6} \mathrm{TRG}_{-} \mathrm{MTB}_{\mathrm{i}}+\alpha_{7} \mathrm{TRG}_{-} \mathrm{SAL} \_\mathrm{GRO}_{\mathrm{i}}+\alpha_{8} \mathrm{TRG}_{-} \mathrm{ROA}_{\mathrm{i}} \\
& +\alpha_{9} \text { ACQ_MTB }{ }_{i}+\alpha_{10} \text { TRG_RET_DV }{ }_{i}+\alpha_{11} \text { ACQ_RET_DV } i \\
& +\alpha_{13} \text { DEAL_SIZE }{ }_{i}+\text { Year dummies }+ \text { Target industry dummies }+\varepsilon
\end{aligned}
$$

\begin{tabular}{|c|c|c|c|c|}
\hline & Exp. Sign & Coeff. & & t-stat \\
\hline TRG_RD & - & -1.246 & $* * *$ & -2.78 \\
\hline TRG_AD & + & 0.773 & & 0.60 \\
\hline TRG_BS_GDWL & + & 0.564 & $* * *$ & 4.13 \\
\hline TRG_BS_INTAN & - & 0.319 & & 1.17 \\
\hline TRG_PPE & - & -0.073 & $*$ & -1.81 \\
\hline TRG_MTB & + & 0.004 & $* *$ & 2.11 \\
\hline TRG_SAL_GRO & + & -0.031 & & -0.85 \\
\hline TRG_ROA & + & 0.138 & & 1.41 \\
\hline ACQ_MTB & + & 0.002 & & 0.32 \\
\hline TRG_RET_DV & + & -0.070 & & -0.49 \\
\hline ACQ_RET_DV & $?$ & 0.021 & & 1.23 \\
\hline INDSAME & + & 0.059 & & 1.13 \\
\hline DEAL_SIZE & + & -0.015 & & -1.19 \\
\hline Year dummies & & \multirow{2}{*}{\multicolumn{3}{|c|}{ Included }} \\
\hline Sector dummies & & \multicolumn{2}{|c|}{ Included } & \\
\hline Constant & & 0.522 & $* * *$ & 3.51 \\
\hline $\mathrm{N}$ & & & & 308 \\
\hline $\mathrm{R}^{2}$ & & & & 0.320 \\
\hline Adj. $R^{2}$ & & & & 0.246 \\
\hline
\end{tabular}

$* * *, * *$, and $*$ denote significance (two-tailed) at the $0.01,0.05$, and 0.10 levels, respectively.

Table 2, Panel A presents the results of the OLS estimation of model (1) and reports White-corrected t-statistics.

GOODWILL = Goodwill divided by deal value. TRG_RD $=$ Target's R\&D expense over the year before the deal announcement divided by deal value. TRG_AD = Target's advertising expense over the year before the deal announcement divided by deal value. TRG_BS_GDWL = Target's preacquisition goodwill at the year-end prior to the deal announcement divided by deal value. TRG_BS_INTAN = Target's pre-acquisition other intangible assets at the year-end prior to the deal announcement divided by deal value. TRG_PPE = Target's gross property plant \& equipment at the year-end prior to the deal announcement divided by deal value. TRG_MTB $=$ Target's market-to-book ratio at the year-end prior to the deal announcement. TRG_SAL_GRO $=$ Target's average sales growth over the two years before the deal announcement year. TRG_ROA = Target's EBITDA over the year before the deal announcement divided by total assets at the beginning of the year. ACQ_MTB = Acquirer's market-to-book ratio. TRG_RET_DV = Target's dollar amount of stock returns over the three-day window around the announcement of the acquisition divided by deal value. ACQ_RET_DV $=$ Acquirer's dollar amount of stock returns over the three-day window around the announcement of the acquisition divided by deal value. INDSAME $=1$ if the acquirer and the target are from the same GICS sector, and 0 otherwise. DEAL_SIZE = natural logarithm of deal value. 
Panel B: Descriptive statistics of the level of Abnormal Goodwill

\begin{tabular}{lrrrrrrrr}
\hline & $\mathrm{N}$ & \multicolumn{1}{c}{ Mean } & St. Dev & \multicolumn{1}{c}{ Min } & \multicolumn{1}{c}{ 1st Q. } & \multicolumn{1}{c}{ Median } & 3rd. Q & \multicolumn{1}{c}{ Max } \\
\cline { 2 - 9 } ExpGW & 308 & 0.523 & 0.147 & 0.066 & 0.425 & 0.527 & 0.625 & 1.028 \\
AbGW & 308 & 0.000 & 0.215 & -0.667 & -0.140 & -0.003 & 0.142 & 0.580 \\
\hline
\end{tabular}

Table 3, Panel B presents descriptive statistics for Expected Goodwill (ExpGW) computed with fitted values from model (1) and Abnormal Goodwill (AbGW) computed as the residuals of model (1). 
Table 3

Investors' reaction to purchase price allocation

$\mathrm{CAR}_{[t-1 ; t+4]}=\alpha_{0}+\alpha_{1} \mathrm{GW}_{\mathrm{i}}+\alpha_{2} \mathrm{SCORE}_{\mathrm{i}}+\alpha_{3}$ MATERIALITY $_{\mathrm{i}}+\alpha_{4}$ DISP_TP $_{\mathrm{i}}+\alpha_{5} \mathrm{FORM}_{\mathrm{i}}+\varepsilon$

\begin{tabular}{|c|c|c|c|c|c|c|c|c|c|c|c|c|c|}
\hline & & \multicolumn{3}{|c|}{ (1) } & \multicolumn{3}{|c|}{ (2) } & \multicolumn{3}{|c|}{ (3) } & \multicolumn{3}{|c|}{ (4) } \\
\hline & Exp. Sign & Coeff. & & t-stat & Coeff. & & t-stat & Coeff. & & t-stat & Coeff. & & t-stat \\
\hline GOODWILL & ? & -0.020 & ** & -2.14 & & & & & & & & & \\
\hline ExpGW & $\mathrm{ns}$ & & & & -0.016 & & -0.85 & & & & -0.016 & & -0.86 \\
\hline $\mathrm{AbGW}$ & - & & & & & & & -0.022 & ** & -1.99 & -0.022 & $* *$ & -2.00 \\
\hline Control variables & & & & & & & & & & & & & \\
\hline SCORE & + & -0.004 & & -0.41 & -0.004 & & -0.43 & -0.005 & & -0.52 & -0.004 & & -0.43 \\
\hline MATERIALITY & - & -0.007 & $* *$ & -2.26 & -0.007 & $* *$ & -2.22 & -0.008 & $* *$ & -2.28 & -0.008 & $* *$ & -2.25 \\
\hline DISP_TP & ? & 0.010 & & 1.03 & 0.009 & & 0.89 & 0.010 & & 1.01 & 0.010 & & 1.03 \\
\hline FORM & ? & 0.008 & & 1.51 & 0.008 & & 1.50 & 0.008 & & 1.52 & 0.008 & & 1.52 \\
\hline Constant & & 0.002 & & 0.28 & 0.001 & & 0.05 & -0.008 & & -1.09 & 0.000 & & 0.01 \\
\hline $\mathrm{N}$ & & 308 & & & 308 & & & 308 & & & 308 & & \\
\hline Adj. $R^{2}$ & & 0.026 & & & 0.014 & & & 0.023 & & & 0.023 & & \\
\hline
\end{tabular}

$* * *, * *$, and $*$ denote significance (two-tailed) at the $0.01,0.05$, and 0.10 levels, respectively.

Table 3 presents the results of the OLS estimation of model (2) and reports White-corrected t-statistics.

ACQ_CAR ${ }_{[t-1 ; t+4]}=$ Acquirer's cumulative abnormal returns computed from the day before the first release of the PPA to +4 days after the release of PPAs in SEC filings. Abnormal returns are computed with the market model. $\mathrm{GW}=$ one of the following three variables: GOODWILL $=$ Goodwill divided by deal value; ExpGW = Expected Goodwill computed with fitted values from model (1); AbGW = Abnormal Goodwill estimated as the residuals of model (1). SCORE $=$ Self-constructed measure of disclosures provided about PPAs. MATERIALITY $=$ Deal value divided by acquirer's market value of equity. DISP_TP $=$ highest analyst forecast target price minus lowest analyst forecast target price divided by the mean target price in the month prior to the SEC filing. 


\section{Table 4}

Investors' reaction to Abnormal Goodwill and type of deals

Panel A: Mean seven-day cumulative abnormal returns for Good vs. Bad Deals and levels of Abnormal Goodwill

\begin{tabular}{cccc}
\hline & $\mathrm{AbGW}<0$ & $\mathrm{AbGW}>0$ & $\Delta$ \\
\hline Good Deal & -0.0017 & -0.0051 & -0.0034 \\
& $\mathrm{n}=76$ & $\mathrm{n}=63$ & \\
Bad Deal & -0.0040 & -0.0182 & -0.0142 \\
& $\mathrm{n}=81$ & $\mathrm{n}=88$ & \\
\hline$\Delta$ & -0.0023 & -0.0131 & \\
\hline
\end{tabular}


Panel B: Market reaction to Abnormal Goodwill conditional on type of deal

$\mathrm{CAR}_{[t-1 ; t+i]}=\alpha_{0}+\alpha_{1}$ Good_Deal $_{\mathrm{i}}+\alpha_{2}$ ExpGW $_{\mathrm{i}}+\alpha_{3} \mathrm{AbGW}_{\mathrm{i}}+\alpha_{4} \mathrm{Good}_{-}$Deal $_{\mathrm{i}}^{*} \mathrm{AbGW}_{\mathrm{i}}+\alpha_{5} \mathrm{SCORE}_{\mathrm{i}}+\alpha_{6} \mathrm{MATERIALITY}_{\mathrm{i}}+\alpha_{7} \mathrm{DISP}_{-} \mathrm{TP}_{\mathrm{i}}+\alpha_{8} \mathrm{FORM}_{\mathrm{i}}+\varepsilon$

\begin{tabular}{|c|c|c|c|c|c|c|c|c|c|c|}
\hline & \multirow[b]{2}{*}{ Exp. Sign } & \multicolumn{3}{|c|}{$\operatorname{CAR}_{[t-1 ; t+3]}$} & \multicolumn{3}{|c|}{$\operatorname{CAR}_{[t-1 ; t+4]}$} & \multicolumn{3}{|c|}{$\operatorname{CAR}_{[t-1 ; t+5]}$} \\
\hline & & Coeff. & & t-stat & Coeff. & & t-stat & Coeff. & & t-stat \\
\hline Good_Deal & $?$ & 0.005 & & 1.11 & 0.006 & & 1.25 & 0.008 & & 1.45 \\
\hline ExpGW & ns & -0.021 & & -1.23 & -0.017 & & -0.94 & -0.023 & & -1.18 \\
\hline AbGW & - & -0.038 & $* * *$ & -3.05 & -0.040 & $* * *$ & -3.11 & -0.043 & *** & -3.02 \\
\hline Good_Deal * AbGW & + & 0.039 & $*$ & 1.91 & 0.039 & $*$ & 1.75 & 0.042 & $*$ & 1.72 \\
\hline \multicolumn{11}{|l|}{ Control variables } \\
\hline SCORE & + & -0.003 & & -0.33 & -0.003 & & -0.27 & -0.002 & & -0.22 \\
\hline MATERIALITY & - & -0.007 & $* *$ & -2.21 & -0.007 & $* *$ & -2.04 & -0.005 & & -1.45 \\
\hline DISP_TP & $?$ & 0.011 & & 1.21 & 0.009 & & 0.94 & 0.013 & & 1.38 \\
\hline FORM & $?$ & 0.006 & & 1.23 & 0.009 & & 1.56 & 0.007 & & 1.30 \\
\hline Constant & & 0.002 & & 0.17 & -0.003 & & -0.23 & -0.004 & & -0.31 \\
\hline $\mathrm{N}$ & & 308 & & & 308 & & & 308 & & \\
\hline Adj. $R^{2}$ & & 0.034 & & & 0.030 & & & 0.028 & & \\
\hline
\end{tabular}

$* * *, * *$, and $*$ denote significance (two-tailed) at the $0.01,0.05$, and 0.10 levels, respectively.

Table 4, Panel B presents the results of the OLS estimation of model (3) and reports White-corrected t-statistics.

ACQ_CAR $[-1 ;+i]=$ Acquirer's cumulative abnormal returns computed from the day before the first release of the PPA, to $+i$ days after the release of the PPA in the SEC filing. Abnormal returns are computed with the market model. ExpGW = Expected Goodwill computed with fitted values from model (1). AbGW $=$ Abnormal Goodwill estimated as the residuals of model (1) SCORE $=$ Self-constructed measure of disclosures provided about the PPA. MATERIALITY $=$ Deal value divided by acquirer's market value of equity. DISP_TP $=$ highest analyst forecast target price minus lowest analyst forecast target price divided by the mean target price in the month prior to the SEC filing. Good_Deal $=1$ if the acquirer's stock price increases over the three-day window around the announcement of the acquisition, and 0 otherwise. 


\section{Table 5}

Abnormal Goodwill and future impairment

Panel A: Descriptive statistics

\begin{tabular}{lrrrrrr}
\hline & $\mathrm{N}$ & \multicolumn{1}{c}{ Mean } & St. Dev & \multicolumn{1}{c}{ 1st Q. } & Median & 3rd. Q \\
\cline { 2 - 7 } DIMP $[t+1 ; t+2]$ & 308 & 0.163 & 0.370 & 0.000 & 0.000 & 0.000 \\
DIMP $_{[t+1 ; t+2 ; t+3]}$ & 271 & 0.250 & 0.434 & 0.000 & 0.000 & 0.500 \\
IMPpct $[t+1 ; t+2 ; t+3]_{\text {ACQ_DSALE }}^{271}$ & 0.035 & 0.119 & 0.000 & 0.000 & 0.000 \\
ACQ_RET & 308 & 0.236 & 0.232 & 0.088 & 0.177 & 0.321 \\
ACQ_ROA & 308 & 0.090 & 0.319 & -0.102 & 0.053 & 0.222 \\
ACQ_DROA & 308 & 0.169 & 0.104 & 0.111 & 0.155 & 0.228 \\
ACQ_BS_GDWL & 308 & -0.005 & 0.052 & -0.026 & -0.001 & 0.018 \\
ACQ_MTB & 308 & 0.171 & 0.152 & 0.032 & 0.148 & 0.280 \\
ACQ_SIZE & 308 & 3.209 & 2.958 & 1.702 & 2.395 & 3.536 \\
ACQ_LEV & 308 & 8.174 & 1.756 & 6.984 & 7.909 & 9.566 \\
Bad_News & 308 & 0.168 & 0.158 & 0.014 & 0.142 & 0.247 \\
\hline
\end{tabular}

$\operatorname{DIMP}_{[t+1 ; t+2]}=1$ if the acquirer books goodwill impairment during the two years following the acquisition. DIMP $[t+1 ; t+2 ; t+2]=1$ if the acquirer books goodwill impairment during the three years following the acquisition. IMPpct $t_{[t+1 ; t+2 ; t+3]}=$ total goodwill impairment in $t+1, t+2$ and $t+3$ divided by total assets in t. ACQ_DSALE $[t+1 ; t+2]=$ Acquirer's average change in sales during the two years following the acquisition. ACQ_RET ${ }_{[t+1 ; t+2]}=$ Acquirer's average return during the two years following the acquisition. ACQ_ROA ${ }_{[t+1 ; t+2]}=$ Acquirer's average ROA during the two years following the acquisition. ACQ_DROA $[t+1 ; t+2]=$ Acquirer's average change in ROA during the two years following the acquisition. ACQ_BS_GDWL $\mathrm{L}_{[t+1 ; t+2]}=$ Acquirer's goodwill divided by total assets at the end of the year after completion of the acquisition. ACQ_MTB ${ }_{[t+1 ; t+2]}=$ Acquirer's average market-to-book ratio during the two years after completion of the acquisition. ACQ_SIZE $[t+1 ; t+2]=$ Acquirer's average natural logarithm of total assets during the two years after completion of the acquisition. ACQ_LEV ${ }_{[t+1 ; t+2]}=$ Acquirer's average total long-term debt divided by total assets during the two years after completion of the acquisition. Bad_News $[t+1 ; t+2]=1$ if the acquirer's average stock returns are negative in the two years following the acquisition. 
Panel B: Abnormal goodwill and future impairment

\begin{tabular}{lrrr}
\hline & $\operatorname{DIMP}_{[t+1 ; t+2]}$ & $\operatorname{DIMP}_{[t+1 ; t+2 ; t+3]}$ & IMPpct $_{[t+1 ; t+2 ; t+3]}$ \\
\cline { 2 - 4 } $\mathrm{AbGW}<0$ & $14.47 \%$ & $22.53 \%$ & $3.03 \%$ \\
$\mathrm{AbGW}>0$ & $18.24 \%$ & $27.53 \%$ & $3.95 \%$ \\
\hline
\end{tabular}

Panel B shows the frequency and magnitude of impairment based on levels of Abnormal Goodwill. 
Panel C: Abnormal goodwill and likelihood of future impairment

$\operatorname{Pr}\left(\operatorname{DIMP}_{\mathrm{i},[t+1 ; \mathrm{t}+2]}\right)=\alpha_{0}+\alpha_{1} \operatorname{ExpGW}_{\mathrm{i}, \mathrm{t}}+\alpha_{2} \mathrm{AbGW}_{\mathrm{i}, \mathrm{t}}+\alpha_{3} \mathrm{Bad}_{-} \mathrm{News}_{\mathrm{i}[\mathrm{t}+1 ; \mathrm{t}+2]}+\alpha_{4} \mathrm{Bad}_{-} \mathrm{News}_{\mathrm{i}[\mathrm{t}+1 ; \mathrm{t}+2]} * \operatorname{ExpGW}_{\mathrm{i}, \mathrm{t}}+\alpha_{5} \mathrm{Bad}_{-} \mathrm{News}_{\mathrm{i}[t+1 ; \mathrm{t}+2]} * \mathrm{AbGW}_{\mathrm{i}, \mathrm{t}}$

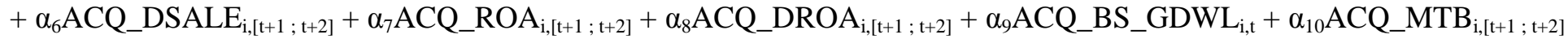
$+\alpha_{11} \mathrm{ACQ}_{-} \mathrm{SIZE}_{\mathrm{i},[\mathrm{t}+1 ; \mathrm{t}+2]}+\alpha_{12} \mathrm{ACQ}_{-} \mathrm{LEV}_{\mathrm{i},[\mathrm{t}+1 ; \mathrm{t}+2]}+$ Acquirer industry dummies $+\varepsilon$

\begin{tabular}{|c|c|c|c|c|c|c|}
\hline & & DIM & $\mathrm{IP}_{[t+1,}$, & & $\operatorname{DIMP}_{[t+1}$ & \\
\hline & Exp. Sign & Coeff. & & z-stat & Coeff. & z-stat \\
\hline ExpGW & $?$ & -1.220 & & -0.64 & -0.799 & -0.56 \\
\hline $\mathrm{AbGW}$ & ? & -1.328 & & -1.07 & -0.292 & -0.34 \\
\hline Bad_News & + & -1.603 & & -1.24 & -0.098 & -0.07 \\
\hline Bad_News *ExpGW & ? & 2.835 & & 1.13 & 0.65 & 0.28 \\
\hline Bad News *AbGW & + & 4.078 & $* *$ & 1.96 & $3.113 * *$ & 2.03 \\
\hline ACQ_DSALE & - & -3.370 & $* *$ & -2.14 & $-3.292 * *$ & -2.54 \\
\hline ACQ_RET & - & -2.270 & $*$ & -1.87 & -1.314 & -0.96 \\
\hline ACQ_ROA & - & -6.407 & $* * *$ & -3.25 & $-6.522 * * *$ & -2.99 \\
\hline ACQ_DROA & - & 0.929 & & 0.17 & 3.776 & 0.48 \\
\hline ACQ_BS_GDWL & + & 3.052 & & 2.52 & $2.553 * *$ & 2.24 \\
\hline ACQ_MTB & - & -0.022 & & -0.40 & 0.052 & 0.84 \\
\hline ACQ_SIZE & ? & -0.14 & & -1.33 & -0.099 & -0.90 \\
\hline ACQ_LEV & + & 3.827 & $* * *$ & 2.71 & $3.961 * * *$ & 3.37 \\
\hline Sector dummies & & & lude & & Incluc & \\
\hline Year dummies & & & clude & & Exclu & \\
\hline Constant & & 1.649 & & 1.03 & 1.53 & 1.13 \\
\hline Pseudo-R ${ }^{2}$ & & & & 0.217 & & 0.184 \\
\hline $\mathrm{N}$ & & & & 308 & & 271 \\
\hline$\alpha_{2}+\alpha_{5}$ & + & 2.750 & $*$ & & $2.821 * *$ & \\
\hline Test $\alpha_{2}+\alpha_{5}=0, p($ Chi 2$)$ & & 0.077 & & & 0.024 & \\
\hline$\alpha_{1}+\alpha_{4}$ & ? & 1.615 & & & -0.149 & \\
\hline Test $\alpha_{1}+\alpha_{4}=0, p($ Chi 2$)$ & & 0.444 & & & 0.940 & \\
\hline
\end{tabular}

$* * *, * *$, and $*$ denote significance (two-tailed) at the $0.01,0.05$, and 0.10 levels, respectively. 
Table 4, Panel C presents the results of the logistic regression of model (4) and reports White-corrected t-statistics.

$\operatorname{DIMP}_{[t+1 ; t+2]}=1$ if the acquirer books goodwill impairment during the two years following the acquisition. DIMP $\mathrm{P}_{[t+1 ; t+2 ; t+3]}=1$ if the acquirer books goodwill impairment during the three years following the acquisition. ExpGW $=$ Expected Goodwill computed with fitted values from model $(1)$. AbGW $\mathrm{t}_{\mathrm{t}}=\mathrm{abnormal}$ goodwill estimated as the residual of model (1). Bad_News $[t+1 ; t+2]=1$ if the acquirer's average stock returns over the two years following the acquisition are negative, and 0 otherwise; ACQ_DSALE $[t+1 ; t+2]=$ Acquirer's average change in sales during the two years following the acquisition. ACQ_RET $_{[t+1 ; t+2]}=$ Acquirer's average return during the two years following the acquisition. ACQ_ROA $[t+1 ; t+2]=$ Acquirer's average ROA during the two years following the acquisition. ACQ_DROA $[t+1 ; t+2]=$ Acquirer's average change in ROA during the two years following the acquisition. ACQ_BS_GDWL ${ }_{t}=$ Acquirer's $_{-}$ goodwill divided by total assets at the end of the year after completion of the acquisition. ACQ_MTB $[t+1 ; t+2]=$ Acquirer's average market-to-book ratio during the two years after completion of the acquisition. ACQ_SIZE $[t+1 ; t+2]=$ Acquirer's average natural logarithm of total assets during the two years after completion of the acquisition. ACQ_LEV $[t+1 ; t+2]=$ Acquirer's average total long-term debt divided by total assets during the two years after completion of the acquisition. Control variables are computed over $t+1, t+2$, and $t+3$ when $\operatorname{DIMP}_{[t+1 ; t+2 ; t+3]}$ is a dependent variable. 
Panel D: Abnormal goodwill and magnitude of future impairment

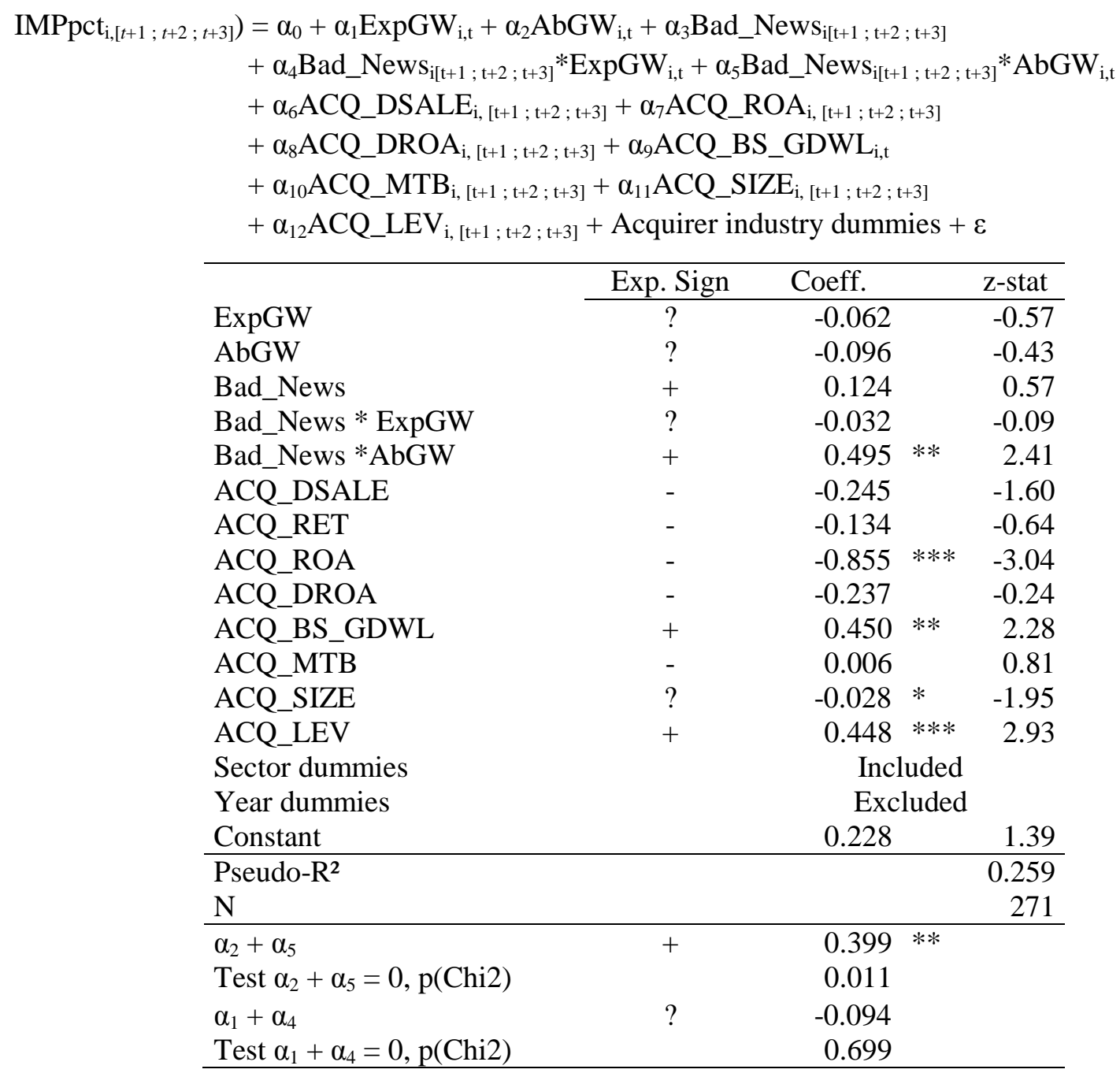

$* * *, * *$, and $*$ denote significance (two-tailed) at the $0.01,0.05$, and 0.10 levels, respectively.

Table 4, Panel C presents the results of the tobit regression of model (5) and reports White-corrected tstatistics.

IMPpct $_{[t+1 ; t+2 ; t+3]}=$ total goodwill impairment in $t+1, t+2$ and $t+3$ divided by total assets in $t$. ExpGW $=$ Expected Goodwill computed with fitted values from model (1). $\mathrm{AbGW}_{\mathrm{t}}=$ abnormal goodwill estimated as the residual of model (1). Bad_News ${ }_{[t+1 ; t+2 ; t+3]}=1$ if the acquirer's average stock returns over the three years following the acquisition are negative, and 0 otherwise; ACQ_DSALE $[t+1 ; t+2 ; t+3]=$ Acquirer's average change in sales during the three years following the acquisition. ACQ_RET $[t+1 ; t+2$; ${ }_{t+3]}=$ Acquirer's average return during the three years following the acquisition. ACQ_ROA ${ }_{[t+1 ; t+2 ; t+3]}$ $=$ Acquirer's average ROA during the three years following the acquisition. ACQ_DROA $[t+1 ; t+2 ; t+3]=$ Acquirer's average change in ROA during the three years following the acquisition. ACQ_BS_GDWL $\mathrm{t}_{\mathrm{t}}=$ Acquirer's goodwill divided by total assets at the end of the year after completion of the acquisition. ACQ_MTB $\mathrm{Bt}_{[t+1 ;+2 ; t+3]}=$ Acquirer's average market-to-book ratio during the three years after completion of the acquisition. ACQ_SIZE $[t+1 ; t+2 ; t+3]=$ Acquirer's average natural logarithm of total assets during the three years after completion of the acquisition. ACQ_LEV $[t+1 ; t+2 ; t+3]=$ Acquirer's average total long-term debt divided by total assets during the three years after completion of the acquisition. 


\section{Table 6}

Abnormal goodwill and future performance

Panel A: Abnormal goodwill and future change in ROA

\begin{tabular}{lrr}
\hline & $\mathrm{N}$ & \multicolumn{1}{c}{$\Delta \mathrm{ROA}_{[\mathrm{t}+1 ; \mathrm{t}+2]}$} \\
\cline { 2 - 3 } $\mathrm{AbGW}_{1}$ & 77 & $2.8 \%$ \\
$\mathrm{AbGW}_{2}$ & 77 & $-0.5 \%$ \\
$\mathrm{AbGW}_{3}$ & 77 & $-0.2 \%$ \\
$\mathrm{AbGW}_{4}$ & 77 & $-0.8 \%$ \\
\cline { 2 - 3 } & 308 & $0.3 \%$ \\
\hline
\end{tabular}

$\Delta \mathrm{ROA}_{[t+1 ; t+2]}=$ Acquirer's average ROA in $t+1$ and $t+2$ following the acquisition minus the assetweighted sum of acquirer's and target's ROA in $t-1$. 
Panel B: Abnormal goodwill and future change in ROA

\begin{tabular}{|c|c|c|c|c|c|}
\hline $\begin{aligned} \Delta \mathrm{ROA}_{[\mathrm{t}+1 ; \mathrm{t}+2]} & = \\
& + \\
& +\end{aligned}$ & $\begin{array}{l}=\alpha_{0}+\alpha_{1} \operatorname{ExpGW}_{\mathrm{i}, \mathrm{t}}+\alpha_{2} \mathrm{Al} \\
+\alpha_{5} \mathrm{ACQ}_{-} \mathrm{MTB}_{\mathrm{i},[\mathrm{t}+1 ; \mathrm{t}+2]}+ \\
+ \text { Year dummies }+ \text { Acqu }\end{array}$ & $\begin{array}{l}\mathrm{GW}_{\mathrm{i}, \mathrm{t}}+\alpha_{3} \mathrm{~A} \\
\alpha_{6} \mathrm{ACQ} \mathrm{SIZ} \\
\text { er industry }\end{array}$ & $\begin{array}{l}\text { DSALE }_{\mathrm{i},[} \\
+1 ; \mathrm{t}+2]+\alpha_{7} \\
\text { imies }+\varepsilon\end{array}$ & ${ }_{7} \mathrm{At+1} ; \mathrm{t+}$ & $\begin{array}{l}+\alpha_{4} \mathrm{AC} \\
\mathrm{ROA}_{\mathrm{i}, \mathrm{t}}\end{array}$ \\
\hline & & Exp. Sign & Coeff. & & t-stat \\
\hline & ExpGW & $?$ & -0.060 & & -1.33 \\
\hline & AbGW & - & -0.065 & $* *$ & -2.41 \\
\hline & Controls & & & & \\
\hline & ACQ_DSALE & + & 0.105 & $* * *$ & 2.87 \\
\hline & ACQ_RET & + & 0.047 & $* *$ & 2.40 \\
\hline & ACQ_MTB & + & 0.007 & $* *$ & 2.55 \\
\hline & ACQ_SIZE & $?$ & -0.002 & & -0.61 \\
\hline & ACQ_ROA & - & -0.209 & $* * *$ & -2.73 \\
\hline & Year dummies & & Incl & luded & \\
\hline & Sector dummies & & Incl & luded & \\
\hline & Constant & & 0.024 & & 0.45 \\
\hline & $\mathrm{N}$ & & & & 308 \\
\hline & Adj. $R^{2}$ & & & & 0.171 \\
\hline
\end{tabular}

$* * *, * *$, and $*$ denote significance (two-tailed) at the $0.01,0.05$, and 0.10 levels, respectively.

Table 5, Panel B presents the results of the OLS estimation of model (6) and reports White-corrected tstatistics.

$\Delta \mathrm{ROA}_{[t+1 ; t+2]}=$ Acquirer's average ROA in $t+1$ and $t+2$ following the acquisition minus the assetweighted sum of acquirer's and target's ROA in $t-1$. ExpGW $=$ Expected Goodwill computed with fitted values from model (1). AbGW = abnormal goodwill resulting from the PPA computed as the residual of model (1). ACQ_DSALE $[t+1 ; t+2]=$ Acquirer's average change in sales during the two years following the acquisition. ACQ_RET = Acquirer's average stock returns during the two years following the acquisition. ACQ_MTB $[t+1 ; t+2]=$ Acquirer's average market-to-book ratio during the two years following the acquisition. ACQ_SIZE $[t+1 ; t+2]=$ Acquirer's average natural logarithm of total assets during the two years after completion of the acquisition. $\mathrm{ROA}_{\mathrm{t}}=$ Acquirer's return on assets during the year of completion of the acquisition.

Acknowledgments. The authors would like to thank Martin Loeb (Editor), two anonymous reviewers, as well as Paul André, Ryan Davies, Thomas Jeanjean, Stephen Lin, Gerald Lobo, Hervé Stolowy, Shiva Sivaramakrishnan and participants at the CAAA Annual Conference, EAA Annual Congress, ESCP-Europe, ESSEC Business School, and CNAM workshops for helpful comments. The authors would also like to thank Ann Gallon for her much appreciated editorial help. 